\title{
Relation between ocean wave activity and wavefield of the ambient noise recorded in northern Poland
}

\author{
Simone Lepore • Marek Grad
}

Received: 12 September 2019 / Accepted: 14 October 2020 /Published online: 4 November 2020

(C) The Author(s) 2020

\begin{abstract}
The temporal and spatial variations of the wavefield of ambient noise recorded at ' 13 BB star' array located in northern Poland were related to the activity of high, long-period ocean waves generated by strong storms in the Northern Indian Ocean, the Atlantic Ocean, and the Northern Pacific Ocean between 2013 and 2016. Once pre-processed, the raw noise records in time- and frequency-domains, and spectral analysis and high-resolution three-component beamforming techniques were applied to the broadband noise data. The power spectral density was analysed to quantify the noise wavefield, observing the primary $(0.04-0.1 \mathrm{~Hz})$ microseism peak and the splitting of the secondary microseism into longperiod $(0.2-0.3 \mathrm{~Hz})$ and short-period $(0.3-0.8 \mathrm{~Hz})$ peaks. The beam-power analysis allowed to determine the changes in the azimuth of noise sources and the velocity of surface waves. The significant wave height, obtained by combining observed data and forecast model results for wave height and period, was analysed to characterise ocean wave activity during strong storms. The comparison of wave activity and beam-power led to distinguish the sources of Rayleigh and Love waves associated to long-period
\end{abstract}

Prof. Grad died suddenly during the revision process. The present work is dedicated to his memory.

S. Lepore $(\bowtie) \cdot$ M. Grad Institute of Geophysics Faculty of Physics, University of Warsaw, ul. Pasteura 5, 02-093 Warsaw, Poland e-mail: Simone.Lepore@ fuw.edu.pl microseisms, of short-period microseisms, and of primary microseisms. High, long-period ocean waves hitting the coastline were found to be the main source of noise wavefield. The source of long-period microseisms was correlated to such waves in the open sea able to reach the shore, whereas the source of primary microseisms was tied to waves interacting with the seafloor very close to the coastlines. The source of short-period microseisms was attributed to strong storms constituted of short-period waves not reaching the coast.

Keywords Ambient noise - Ocean wave activity Primary and secondary microseisms $\cdot$ Numerical modelling $\cdot$ Beamforming

\section{Introduction}

The description of spatial and temporal variations of the ambient noise wavefield is fundamental for many aspects of seismology. Ambient noise can be used not only to infer the characteristics of ocean storms (Ebeling 2012), but also to evaluate the performance of seismic arrays (Wilson et al. 2002) and to investigate the Earth's structure (Shapiro and Campillo 2004; Sabra et al. 2005; Lepore and Grad, 2018). Temporal changes of the noise wavefield during strong ocean storms are consistent with the variations in the wave height and wavewave interaction (Friedrich et al. 1998; Nishida et al. 2008; Ardhuin et al. 2011, 2015; Obrebski et al. 
2012; Davy et al. 2015; Möllhoff and Bean 2016). Azimuth and velocity variations provide information on the location of the ocean storms and on the period of the associated waves (Cessaro and Chan 1989). Therefore, the features of the noise wavefield are linked to height, direction, and period of the ocean waves (Essen et al. 2003). Sources of noise are natural at frequencies lower than $1 \mathrm{~Hz}$, the principal among them including changes of the diurnal temperature and/or atmospheric pressure and wind-driven ocean waves (Demuth et al. 2016; Lepore et al. 2016). Two main mechanisms of noise generation have been recognised at low frequencies. In the $0.1-1-\mathrm{Hz}$ range, the noise, known as the secondary (or double-frequency) microseism, is generated by the interaction of ocean waves travelling with similar frequencies in opposite directions. Below $0.1 \mathrm{~Hz}$, the noise, identified as the primary microseism, is produced by ocean waves interacting with the seafloor near the coastlines (swells) (Longuet-Higgins 1950; Hasselmann 1963; Bromirski and Duennebier 2002; Koper et al. 2009; Kurrle and Widmer-Schnidrig 2010; Ardhuin et al. 2011; Stutzmann et al. 2012; Bromirski et al. 2013; Sergeant et al. 2013; Gualtieri et al. 2015; Lepore and Grad 2018). Despite this dissimilarity, sources of primary and secondary microseisms are both well correlated with ocean wave activity (Stehly et al. 2006; Schimmel et al. 2011; Xiao et al. 2018; Stopa et al. 2019). The source amplitude and modulation, indeed, vary with frequency and bathymetry (Longuet-Higgins 1950; Sergeant et al. 2013).

It is well known that secondary microseisms are dominated by Rayleigh waves (Lee 1935; Lacoss et al. 1969; Tanimoto et al. 2006); however, recent studies have shown that Love waves (Nishida et al. 2008; Juretzek and Hadziioannou 2016; Gal et al. 2017) can be detected in the secondary microseism frequency band. As reported in the literature (Bromirski et al. 2005; Koper and Burlacu 2015; Lepore and Grad 2018; Xiao et al. 2018), the secondary microseism sometimes splits into two peaks, involving the simultaneous activation of two oceanic source regions. The first peak corresponds to the long-period double-frequency (LPDF) microseism $(0.1-0.25 \mathrm{~Hz})$, while the second one, to the short-period double-frequency (SPDF) microseism $(0.25-0.8 \mathrm{~Hz})$. Sources for LPDF and SPDF microseisms have been proposed as nonlinear interactions of ocean waves in the coastal region or in the open ocean. Array techniques allowed observations of long-period and short-period microseisms that can be correlated to strong storms (Haubrich and McCamy 1969; Landès et al. 2010; Koper and Burlacu 2015).

The distribution of the sources of the noise wavefield as a function of time needs to be well understood given the randomness of the noise (Harmon et al. 2010). Beamforming (BF) is known as the most useful technique to analyse spatial and temporal variations of the noise wavefield (Gerstoft and Tanimoto 2007). To identify the areas of noise sources and estimate the wavefield direction, the corresponding noise records at each station of a seismic array are merged in the frequency domain according to the BF method (Rost and Thomas 2002; Roux 2009). Uncertainty in the source location constituted the main problem in investigating the variations of the noise wavefield: several studies facing this difficulty limited the analysis of the source characterization to the vertical component (Stehly et al. 2006; Harmon et al. 2008; Kedar et al. 2008; Yang and Ritzwoller 2008; Ruigrok et al. 2011). To reduce the uncertainty in the source identification, the variations of the noise wavefield were analysed for the $\mathrm{Z}, \mathrm{N}$, and $\mathrm{E}$ components, enabling the attenuation of undesired effects (Hillers et al. 2012; Behr et al. 2013; Lepore and Grad 2018).

The purpose of the present paper is to relate the temporal and spatial variations of the noise wavefield in northern Poland with the hitting on the coast of high, long-period ocean waves generated by strong storms in the Atlantic Ocean, the Northern Indian Ocean, and the Northern Pacific Ocean (Fig. 1a). Taking advantage of the capabilities of the circular, the symmetric structure of the '13 BB star' array (Fig. 1b), equipped with broadband three-component seismometers, we should be able to identify the source of the primary microseisms and to distinguish the sources of Rayleigh and Love waves associated to LPDF microseisms. To study the variations of the noise wavefield amplitude and direction in space and time, spectral analysis and high-resolution three-component $\mathrm{BF}$ are used. At the same time, the ocean wave activity is characterised through the analysis of the observed data and forecast model results from 
international datasets. Throughout the years, high, long-period ocean waves hitting the coast were shown to cause surface waves (Webb et al. 1991; Friedrich et al. 1998; Bromirski and Duennebier 2002; Essen et al. 2003; Schulte-Pelkum et al. 2004; Stehly et al. 2006; Chevrot et al. 2007; Gerstoft and Tanimoto 2007; Kedar et al. 2008; Yang and Ritzwoller 2008; Obrebski et al. 2012; Stutzmann et al. 2012; Ardhuin et al. 2015; Gualtieri et al. 2015; Juretzek and Hadziioannou 2017). Then, the activity of such waves during strong storms can be expected to play a significant role in the wavefield excitations observed in northern Poland.

\section{Noise data interpretation}

\subsection{Data recordings}

The ambient noise was recorded from July 2013 to September 2016 at the ' 13 BB star' array located in northern Poland. The location of the oceans is shown in the radial map centred on the array (Fig. 1a), while the details of the spatial disposition of its stations (Fig. 1b) are given in Lepore et al. (2016). As inferred from the array response function shown in Grad et al. (2015), the array geometry, symmetry, and size enable the assembly of the propagation features of short-, intermediate-, and long-period surface waves constituting the noise wavefield regardless of their azimuth. In this study, we apply two techniques to the recorded noise, namely, spectral analysis and high-resolution three-component beamforming.

\subsection{Pre-processing}

Some pre-processing of the recorded noise is needed for each component before applying the abovementioned techniques. High-resolution methods for data processing are reported in the literature (e.g., Gal et al. 2016). Here we used a method based on Bensen et al. (2007), which already allowed good results in preceding works (Lepore et al. 2016; Lepore and Grad 2018). First, the continuous raw noise records were split into windows of 1-h length, and then, the seismometer instrumental response and the mean and the linear trends were removed. Second, the time-domain normalization was applied to get rid of the effects of large-amplitude events such as earthquakes and non-stationary sources. This accentuates broadband ambient noise, removing a possible lack of clarity. Third, spectral whitening was used to reduce the discrepancies among single-station 1-h windows possibly caused by persistent local narrowband or monochromatic sources.

\subsection{Spectral analysis}

The ambient noise wavefield was characterised by evaluating the spectral features of the noise records. To quantify the noise wavefield, we calculated the power spectral density (PSD) for each hour at the A0 array station for the $\mathrm{Z}, \mathrm{N}$, and $\mathrm{E}$ components using the direct Fourier transform, consistent with the procedure described by Ruigrok et al. (2011). One-hour consecutive PSD curves were stacked in frequency domain for each day, and then, the resulting daily curves were compared with the Peterson (1993) new low noise model (NLNM) and new high noise model (NHNM), taken as reference to define the quality of a seismic array as for the data acquisition. The comparison is shown in Fig. 2, in which the daily curves for the $\mathrm{Z}$ component on several days in 2014 are plotted together with the NLNM and the NHNM curves. On the average, the observed PSD peak in the 0.03-0.1$\mathrm{Hz}$ frequency band is due to the primary microseism, whereas the ones in the $0.2-0.8-\mathrm{Hz}$ band are due to the secondary microseism. A splitting of the secondary microseism into two peaks is also observed: the LPDF microseism in the $0.2-0.3-\mathrm{Hz}$ range and the SPDF microseism in the $0.3-0.8-\mathrm{Hz}$ range. According to Ruigrok et al. (2011) and Lepore et al. (2016), the noise spectrograms were obtained by stacking the 24 consecutive 1-h PSD curves: that allowed the estimation of the variations of the energy level in the wavefield (Demuth et al. 2016). The temporal changes in the energy level, highlighted by the spectrograms at the A0 station, were related to the variations of the ocean wave activity over a defined area, as shown by Ardhuin et al. (2012) and Demuth et al. (2016). 


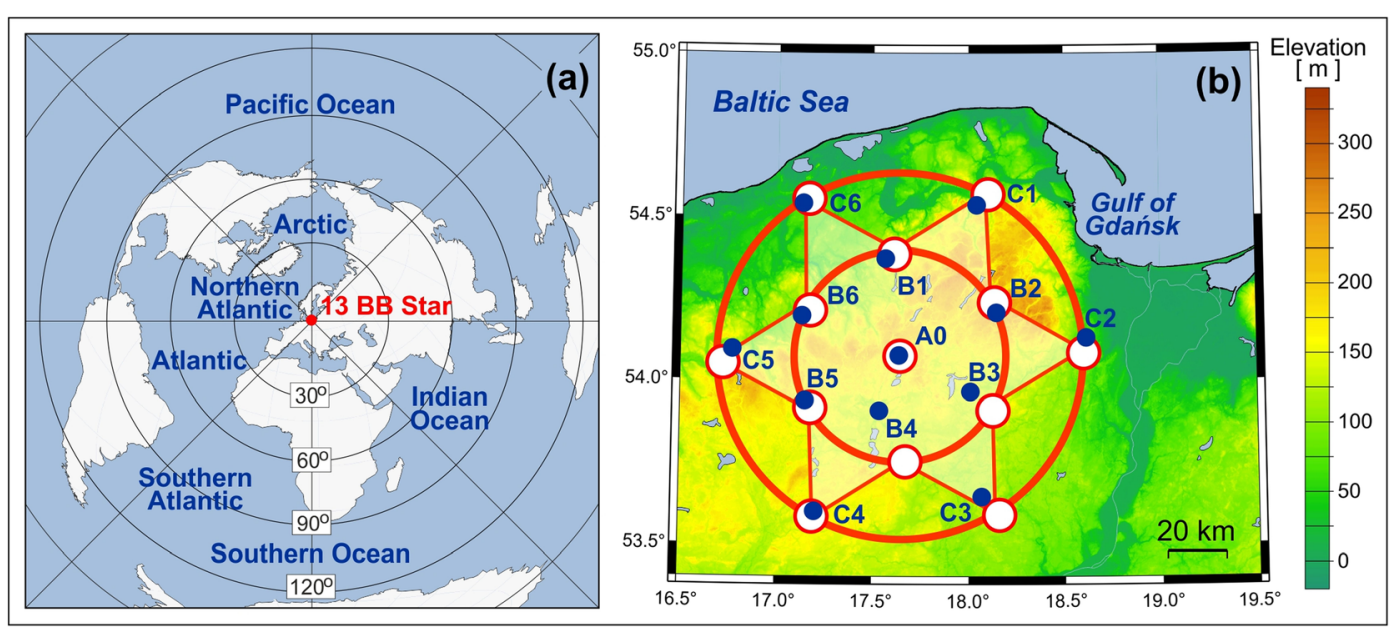

Fig. 1 a Location map of the oceans in the shape of radial map centred on the ' 13 BB star' array in northern Poland. b Map of the ' 13 BB star' array on the background of the topographic map of northern Poland. Red circles show the planned regular geometry of

\subsection{Beamforming}

The BF technique was used to determine changes in the azimuth of noise sources and the velocity of surface waves associated to the noise wavefield (Gerstoft and Tanimoto 2007; Tanimoto and Prindle 2007). The azimuth and velocity variations were estimated through the analysis frequencywavenumber power spectrum associated with the noise wavefield (i.e. beam-power) according to Lepore et al. (2016). For the Z, N, and E components, the corresponding 1-h noise records at all the array stations were combined in the frequency domain to get 1 -h beam-power evaluations through high-resolution three-component BF. In the processing of the $\mathrm{N}$ and $\mathrm{E}$ components, a rotation toward the assumed source direction was applied to appropriately distinguish Rayleigh and Love waves (Lacoss et al. 1969; Behr et al. 2013). The procedures were performed in an appropriate frequency band, whose limits were set at 0.05 and $0.1 \mathrm{~Hz}$, to reduce both beamformer aliasing and near-field effects (Harmon et al. 2008; Behr et al. 2013). As verified in preceding papers (Lepore et al. 2016; Lepore and Grad 2018), undesired effects are less noticeable over the periods of interest. To stabilize its estimation, the beampower was not evaluated separately for each sample of the frequency band, but after splitting the band in bins, its computation was done on the the array network where broadband seismometers are placed in small equilateral triangles with side lengths of about $30 \mathrm{~km}$. The blue dots represent the final locations of the stations (Grad et al. 2015; Lepore et al. 2016)

stacking of the frequency samples within each bin (Ruigrok et al. 2011). Then, the beamformer output was estimated for each hour as a function of azimuth $\left(0-359^{\circ}\right)$ and slowness (inverse of velocity; $0.1-0.5 \mathrm{~s} / \mathrm{km}$ ) in the entire frequency band. The values of first and secondary peaks were extracted from each beam-power amplitude evaluation. The described procedure was repeated for the whole acquisition period, being aware that an irregular distribution of the noise sources or a low number of operative stations could lead to erroneous results (van Dalen et al. 2014). Hence, the study of the array resolution for the BF application, described in Appendix 1, was performed according to Seydoux et al. (2016). Based on the analysis of spatial aliasing, caused by the array response (Grad et al. 2015), seven stations were assumed as the threshold to get a satisfactory array resolution.

\section{Ocean wave activity}

The ocean wave activity during strong storms was described by the analysis of an operative parameter useful to analyse ocean storms, namely, the significant wave height (SWH). As reported by Ardhuin et al. (2012), the SWH is defined as the average height between one-third and one-tenth of the highest wave in the wave spectrum, obtained by 

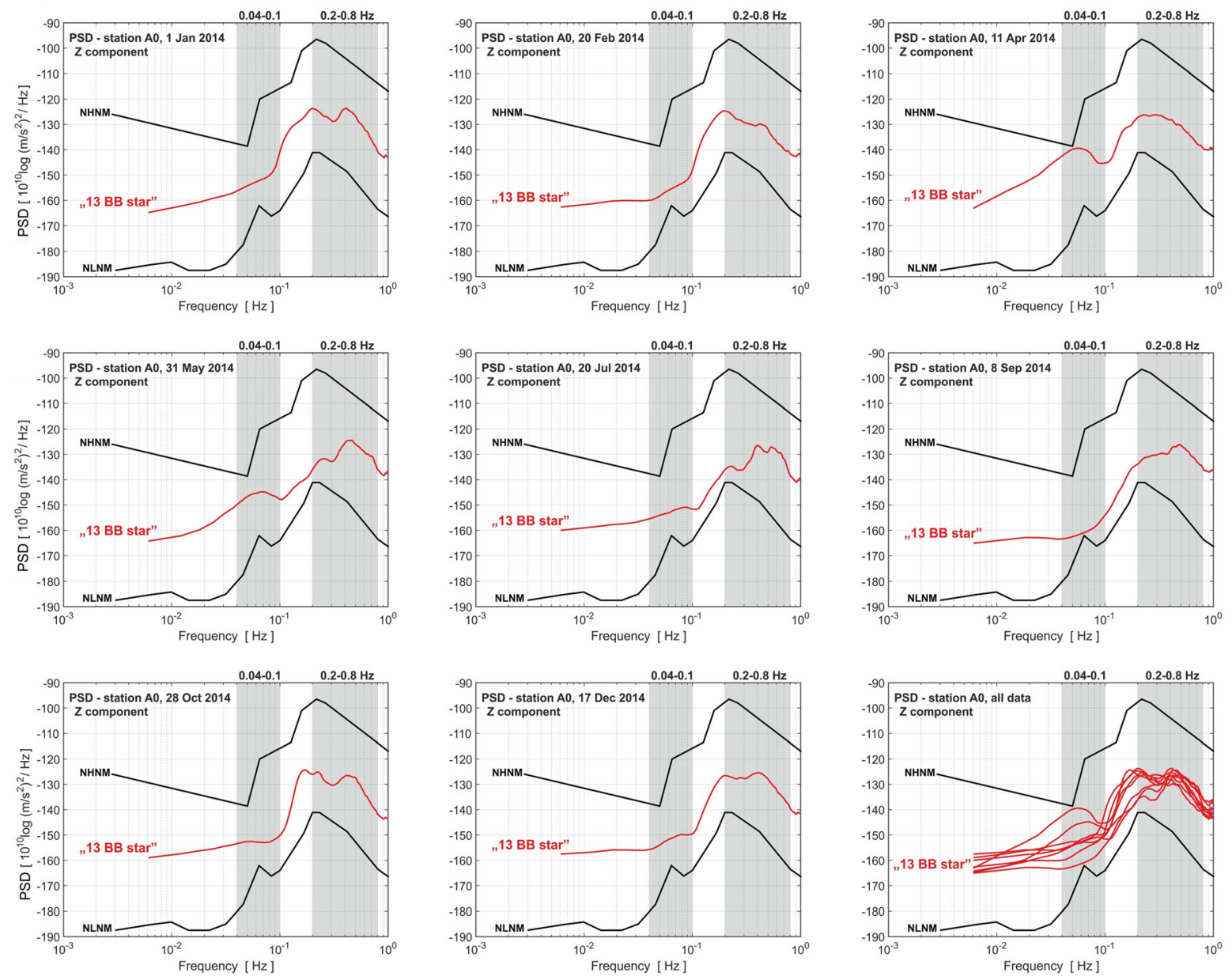

Fig. 2 Daily PSD curves on several days in 2014 (plots 1-8) at A0 station of the ' $13 \mathrm{BB}$ star' array for the Z component compared with the new low noise model (NLNM) and the new high noise model (NHNM) from Peterson (1993). The whole set of curves is compared with the NLNM and NHNM models in the plot at the bottom-right corner. The typical frequency bands for primary microseism peak $(0.04-0.1 \mathrm{~Hz})$ and secondary microseism peak $(0.2-0.8 \mathrm{~Hz})$ are highlighted in light grey the combination of observed data and forecast model results for the wave height and period (Demuth et al. 2016) including wave-wave interactions and swells (the whole procedure to get SWH is reported in Appendix 2). The observed data are provided by the National Center for Atmospheric Research (NCAR) reanalysis project (Kalnay et al. 1996) and presented in geographic coordinates with a 1-h time resolution (International Comprehensive Ocean-Atmosphere Data Set [ICOADS], Freeman et al. 2017). The forecast model results are supplied by the European Centre for Medium-Range Weather Forecasts (ECMWF) program (Palmer et al. 1990) and shown in geographic coordinates with a 6-h time resolution (ERA-Interim project, Dee et al. 2011). The global distribution of the resulting SWH $(0-5 \mathrm{~m})$, shown (Fig. 3) in spherical coordinates as a function of the azimuth $\left(0-359^{\circ}\right)$ and the distance between the storm sources and the A0 station $(0-12,500 \mathrm{~km})$ with a 6-h time resolution, was related to the temporal and spatial variations of the noise wavefield through the comparison with the preceding 6-h stacking of 1-h beam-power evaluations (Kurrle and Widmer-Schnidrig 2010; Ardhuin et al. 2012; Demuth et al. 2016). 

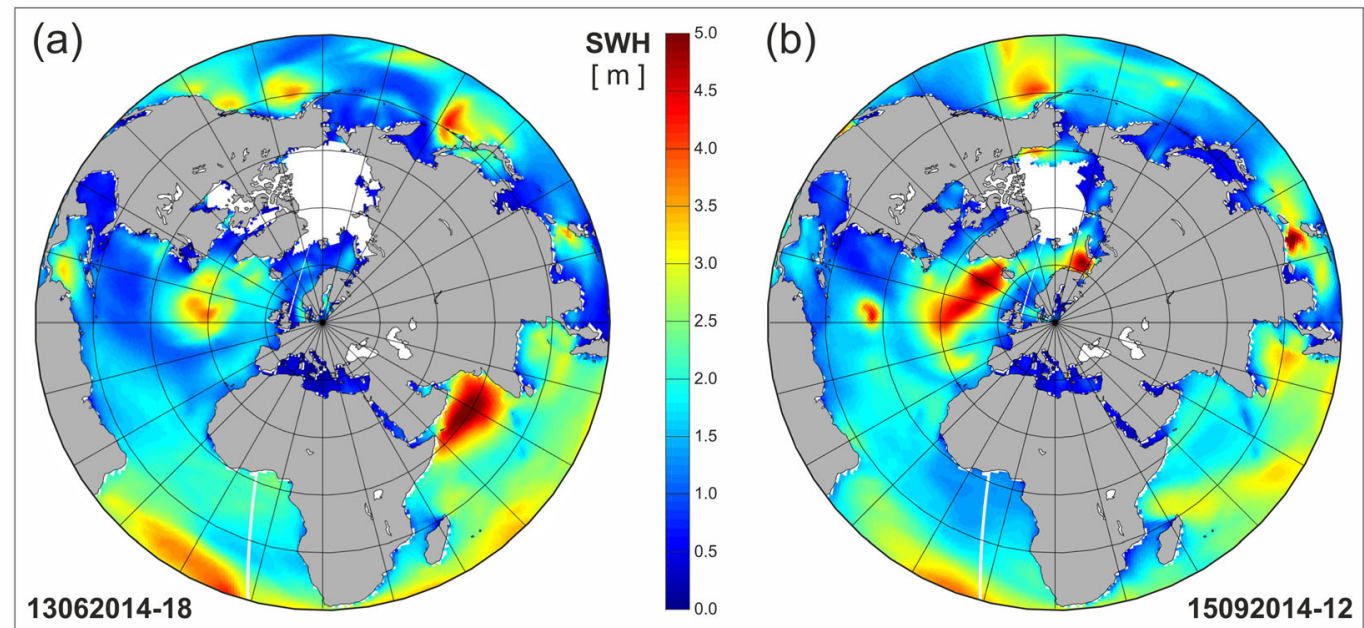

Fig. 3 Global distribution of the significant wave height (SWH, 0-5 m) for a June 13, 2014, hour 18 and b September 15, 2014, hour 12 , shown in the shape of coloured radial plots centred on the A0 array station as a function of the azimuth $\left(0-359^{\circ}\right)$ and the

\section{Results}

The spatial and temporal variations of the ambient noise wavefield, as well as the global distribution of SWH, are analysed to characterise the strong storms in the Atlantic Ocean, the Northern Pacific Ocean, and the Northern Indian Ocean. Among the several storms observed in the 3 years of noise recordings, the ones studied in detail are those that occurred on June 9-16 and September 12-19, 2014. The source regions of storms were identified by the analysis of SWH (Fig. 3). To estimate the storm duration, instead, ambient noise analysis was performed for both the vertical and horizontal components. However, as commonly reported in the literature (Kurrle and Widmer-Schnidrig 2010; Demuth et al. 2016), only the $Z$ component is shown in Figs. 4, 5, 6, and 7.

\subsection{Global distribution of significant wave height}

The global distributions of SWH are shown in Fig. $3 \mathrm{a}$ and $\mathrm{b}$ in the shape of coloured radial plot centred on the A0 array station as a function of azimuth and source station distance, mapping the longitude-latitude distribution of SWH values on the azimuthal equidistant projection of the Earth. In both the chosen time periods, SWH is reported only for those days in which areas $\left(\geq 10^{\circ}\right.$ and distance between the storm sources and the A0 station (0$12,500 \mathrm{~km})$. The dates in the a bottom-left and $\mathbf{b}$ bottom-right extremities are reported as daymonthyear-hour

$\geq 1500 \mathrm{~km}$ ) showing values $\geq 3.5 \mathrm{~m}$ (SWH maxima), attributable to the source regions of strong storms, can be clearly identified. On June 13, 2014, hour 18 (Fig. 3a), SWH maxima are observed in the Northern Pacific Ocean between 30 and $45^{\circ}$, in the Northern Indian Ocean between 105 and $135^{\circ}$, and in the Southern Atlantic Ocean between 195 and $225^{\circ}$. On September 15, 2014, hour 12 (Fig. 3b), SWH maxima are observed near the coast of Lapland between 15 and $35^{\circ}$, in the Atlantic Ocean between 260 and $320^{\circ}$, and in the Northern Pacific Ocean near the Canadian coast between 345 and $360^{\circ}$ and near the Russian coast around $70^{\circ}$. Therefore, the Northern Pacific Ocean, the Northern Indian Ocean, the Southern Atlantic Ocean, and the Northern Atlantic Ocean are source regions of strong storms during the 3-year acquisition period.

\subsection{Ambient noise variations}

Spectrograms for the $\mathrm{Z}$ component resulting from the stacking of 1-h consecutive PSD curves for 1 day are shown for June 9-16 (Fig. 4a) and September 12-19, 2014 (Fig. 4b). The noise wavefield is continuously present during the whole period in two main frequency bands, namely, $0.03-1$ and 2-50 Hz. In the former frequency range, corresponding to the primary and secondary microseisms, the wavefield is composed mainly 


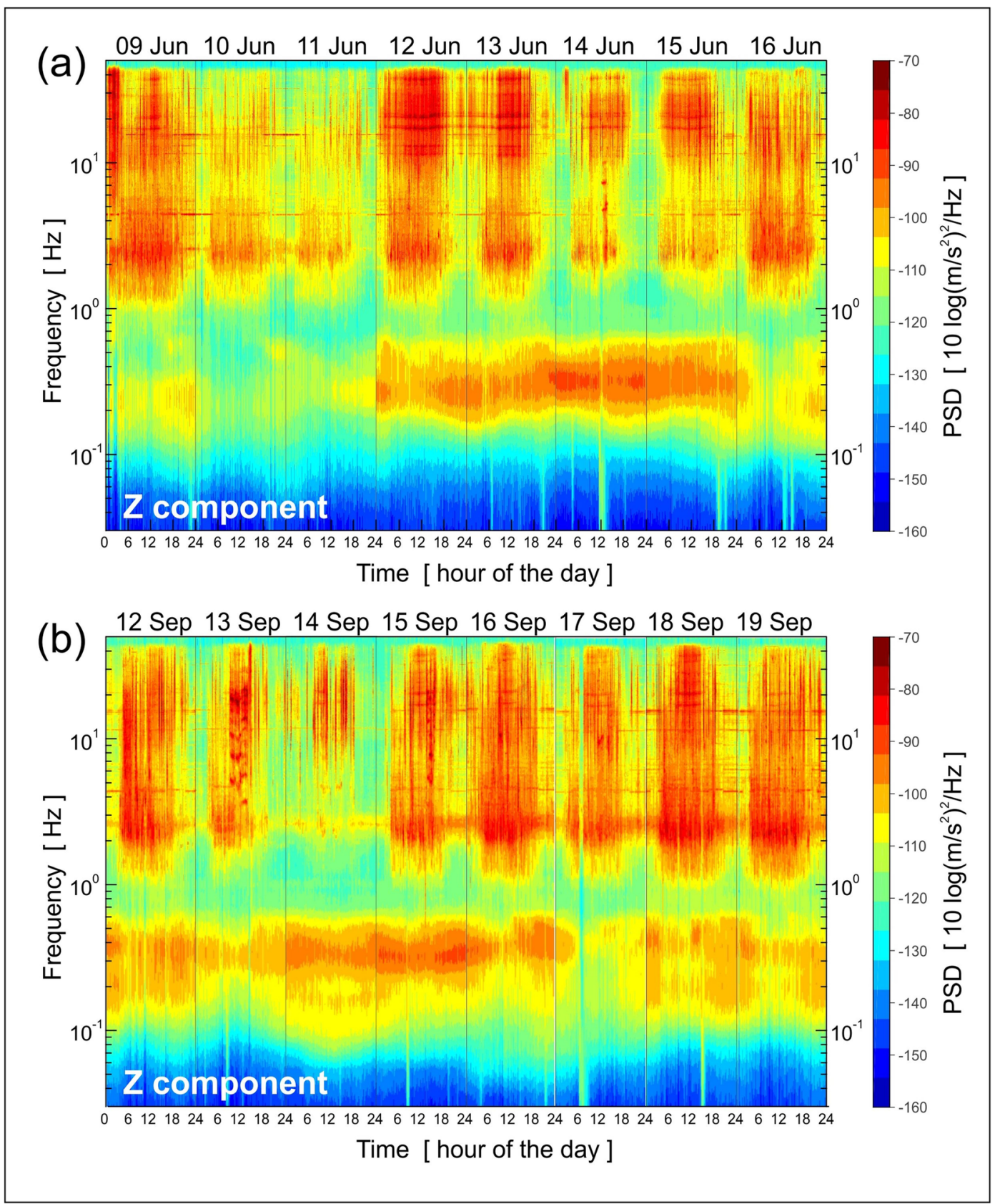

Fig. 4 Spectrograms for the $\mathrm{Z}$ component resulting from the stacking of 24 consecutive 1-h PSD curves of ambient noise recorded at the A0 station on a June 9-16 and b September 12-19, 2014

of surface waves generated by high, long-period ocean waves. PSD ranges between -105 and $-85 \mathrm{~dB}$ in the $0.2-0.6-\mathrm{Hz}$ frequency range, from June 11 to June 15 (Fig. 4a) and between the same values in the same range, from September 14 to September 17 (Fig. 4b). High PSD values correspond to high SWH values associated to strong ocean storms as it comes out from Fig. 3.
Therefore, in both spectrograms, the PSD is higher during the days in which a strong storm is present and lower in the remaining days.

The daily plots of 1-h PSD curves as a function of frequency for the $\mathrm{Z}$ component at the $\mathrm{A} 0$ station are shown for June 9-16 (Fig. 5a) and September 12-19, 2014 (Fig. 5b). For each plot, the first curve from the 


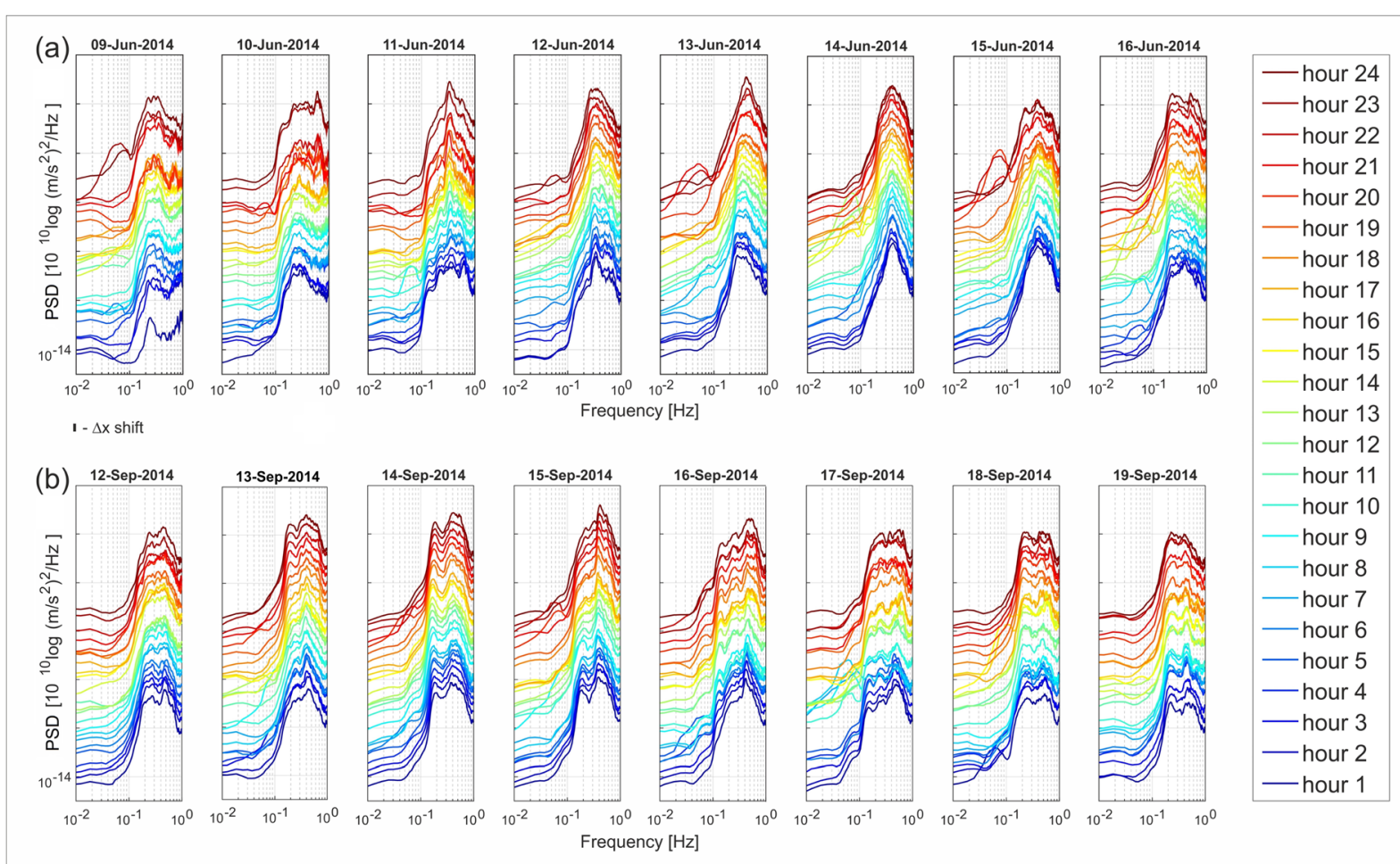

Fig. 5 Daily plots of 1-h PSD curves as a function of frequency for the $\mathrm{Z}$ component at the A0 station on a June 9-16 and b September 12-19, 2014. For each plot, the first curve from the bottom (hour 1) is in its proper scale, whereas all the other curves

bottom (hour 1) is in its proper scale, whereas all the other curves are moved up by a fixed $\Delta \mathrm{x}$ shift. The set of colours used for the 24 curves is reported in the plot legend. For the primary microseism $(0.04-0.1 \mathrm{~Hz})$, the number of maxima and the related amplitude change on the basis of the intensity of the ocean storm. In this frequency band, several significant maxima are detected for some curves during the stormy days (June 11-15 and September 14-17). For the secondary microseism (0.2$0.8 \mathrm{~Hz}$ ), the splitting of the secondary microseism into two peaks is observed (Lepore and Grad 2018): the LPDF microseism in the $0.2-0.3-\mathrm{Hz}$ range, and the SPDF microseism in the $0.3-0.8-\mathrm{Hz}$ range. That splitting is present on June 13, 14, and 15 (Fig. 5a) and on all the stormy days in September (Fig. 5b).

The azimuth and velocity values (Figs. 6 and 7, respectively) are extracted for each hour from the first and second peaks of the beam-power in the $0.05-0.1-\mathrm{Hz}$ band. To deal only with strong storms, values whose amplitude is greater than $6 \mathrm{~dB}$ was used. Those obtained from the first peak are highlighted by filled blue circles, while the are progressively moved up by the multiples of a fixed $\Delta \mathrm{x}$ shift (marked at the centre-left of the figure). The set of colours used for the 24 curves is reported in the side legend

ones from the second maximum are marked by empty red circles. The width of the circles was fixed according to the maximum angular resolution in the beam-power plots, which is $\sim 10^{\circ}$. The variations of the azimuth of noise sources are shown in the scatter plots for the $\mathrm{Z}$ component on June 8-17 (Fig. 6a) and September 11-20, 2014 (Fig. $6 b)$. From June 11-14, a high concentration of blue and red circles is observed within the 30 $50^{\circ}, 70-90^{\circ}, 110-130^{\circ}, 190-220^{\circ}$, and $260-310^{\circ}$ azimuth ranges. Analogously, from September 1417 , a high concentration of circles is seen within the $15-30^{\circ}, 50-70^{\circ}, 250-330^{\circ}$, and $330-360^{\circ}$ azimuth ranges (Fig. 6b). These values are coherent with those reported in the literature for the Atlantic Ocean (Friedrich et al. 1998; Kurrle and Widmer-Schnidrig 2010) and the Indian Ocean (Davy et al. 2015), taking into account the changes of the bathymetry at the microseims source location (Sergeant et al. 2013). The variations of surface waves velocity are shown in the scatter plots for the $\mathrm{Z}$ component on June 8-17 (Fig. 


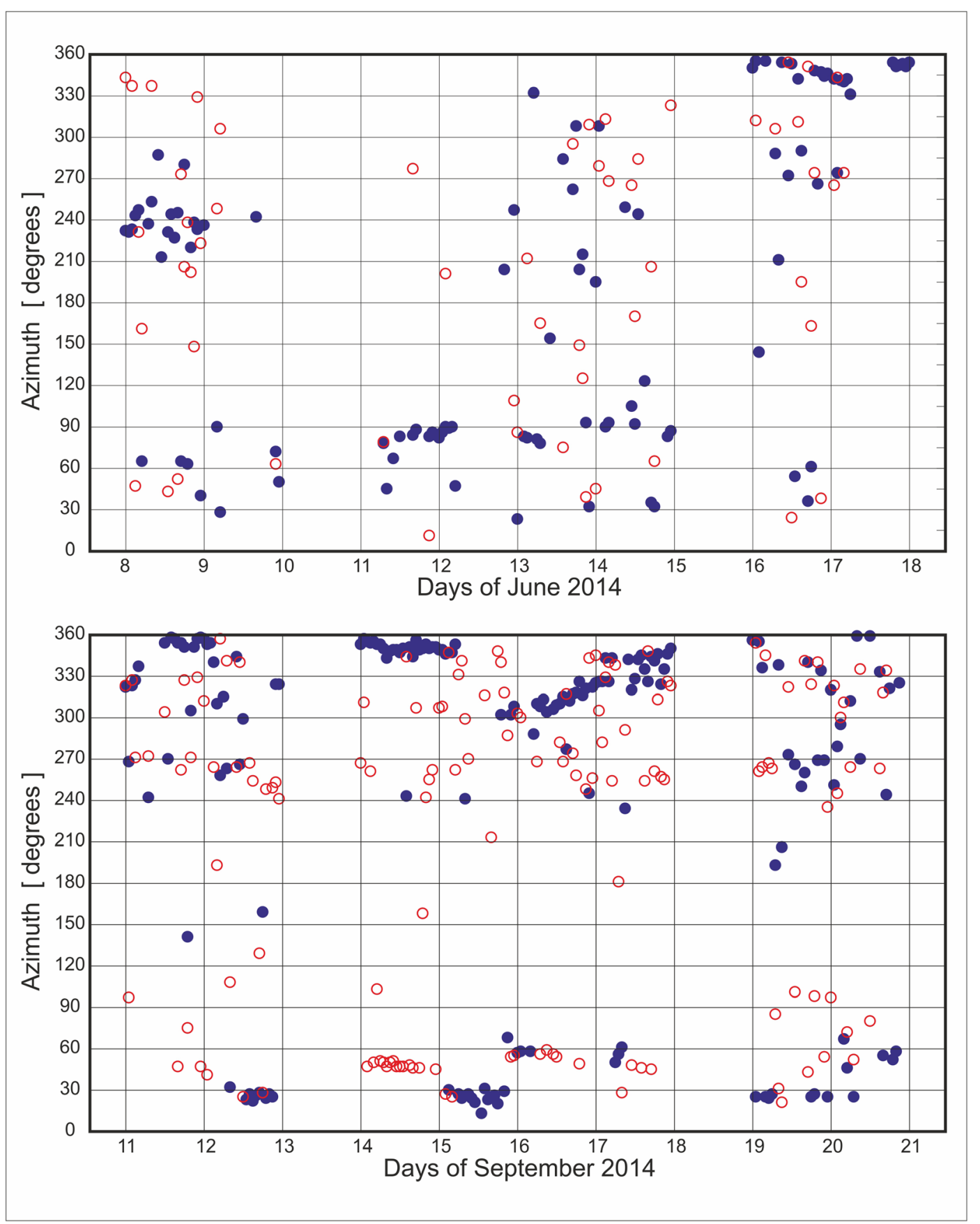

Fig. 6 Variations of the azimuth of noise sources calculated for the first and second peaks of the beam-power in the $0.05-0.1-\mathrm{Hz}$ band. The azimuth values for each hour are shown in the scatter plots for the $\mathrm{Z}$ component in June 8-17 (upper panel) and September 11-20 (lower panel), 2014 periods. Only the values for

7a) and September 11-20 (Fig. 7b). A high concentration of blue and red circles is observed within the $2.0-4.0 \mathrm{~km} / \mathrm{s}$ range in both periods, as which the amplitude is greater than $-6 \mathrm{~dB}$ are included in the plots: those related to the first peak are highlighted by filled blue circles, while the ones linked to the second peak are marked by empty red circles

expected from literature papers concerning surface wave dispersion effects (Essen et al. 2003; Schimmel et al. 2017; Lepore and Grad 2018). 


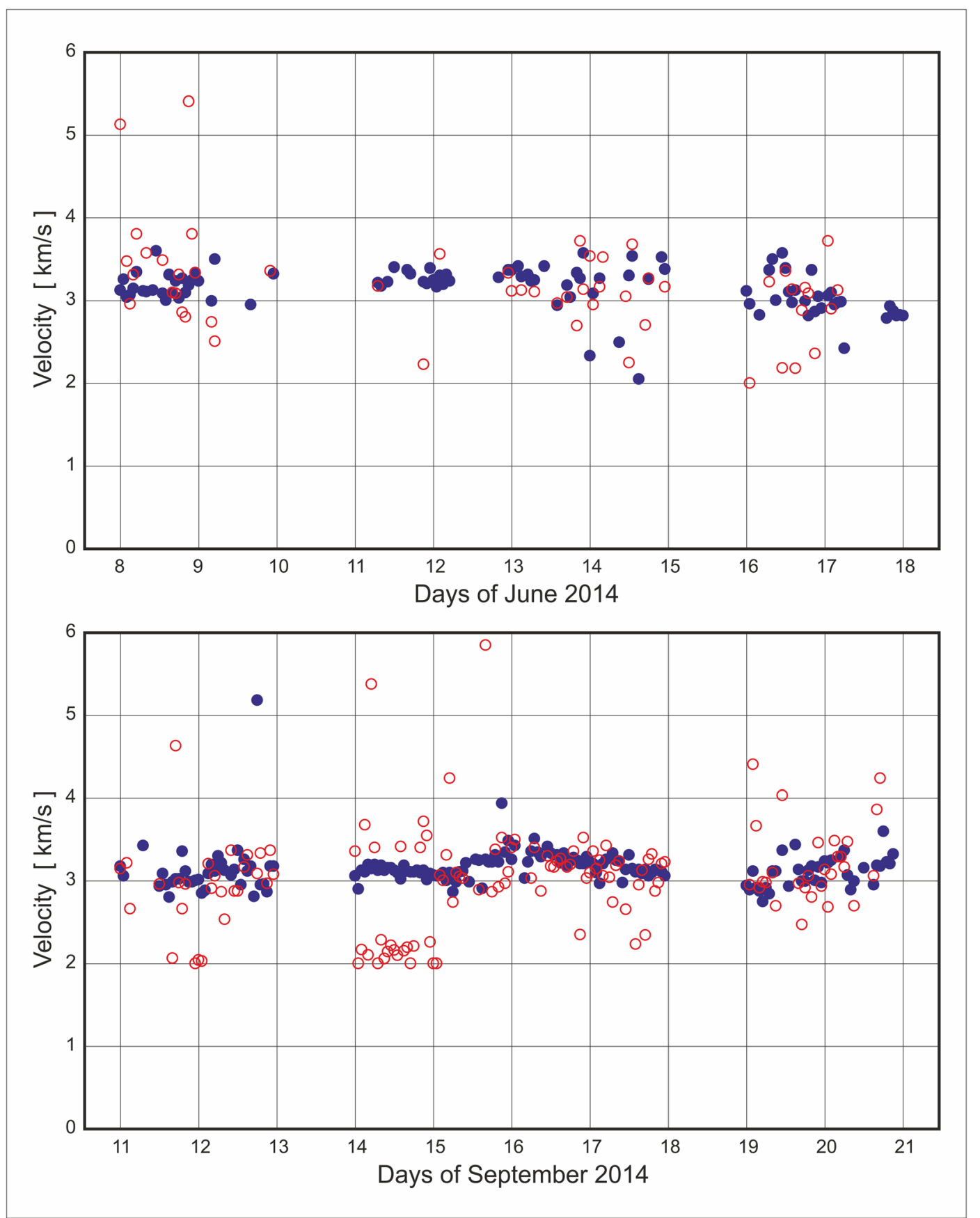

Fig. 7 Variations of surface wave velocity calculated for the first and second maxima of the beam-power in the $0.05-0.1 \mathrm{~Hz}$ band. The velocity values for each hour are shown in the scatter plots for the $\mathrm{Z}$

\section{Discussion}

In previous papers from this laboratory, the impact of wind on the ambient noise in Northern Poland (Lepore et al. 2016) and the spectral features of component in June 8-17 (upper panel) and September 11-20 (lower panel), 2014 periods. Only the values for which the amplitude is greater than $-6 \mathrm{~dB}$ are included in the plots: symbols are as in Fig. 6

noise microseisms whose wavefield is coming from North Sea and Baltic Sea (Lepore and Grad 2018) have been analysed. Other studies (Kurrle and Widmer-Schnidrig 2010; Ardhuin et al. 2012; Demuth et al. 2016) report that the upward trends 

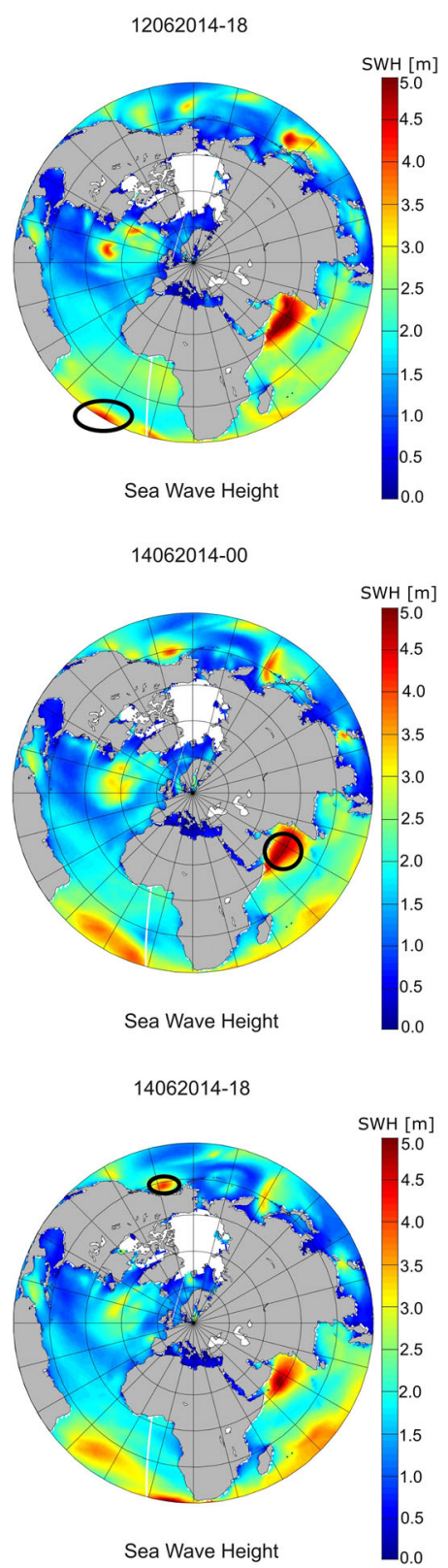

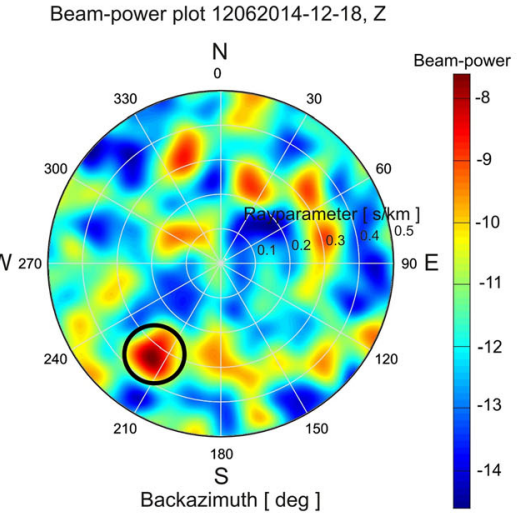

Beam-power plot 13062014-18-24, Z

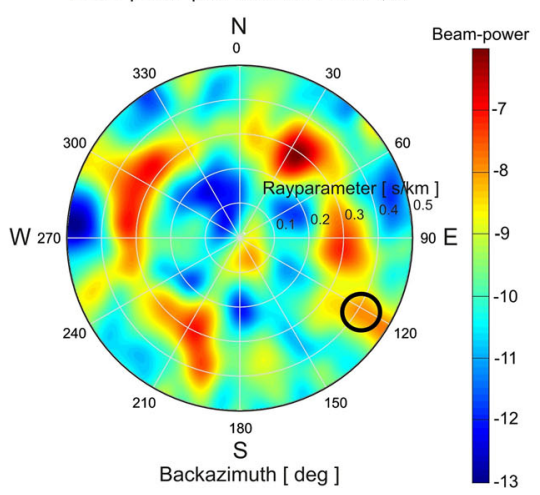

Beam-power plot 14062014-12-18, Z

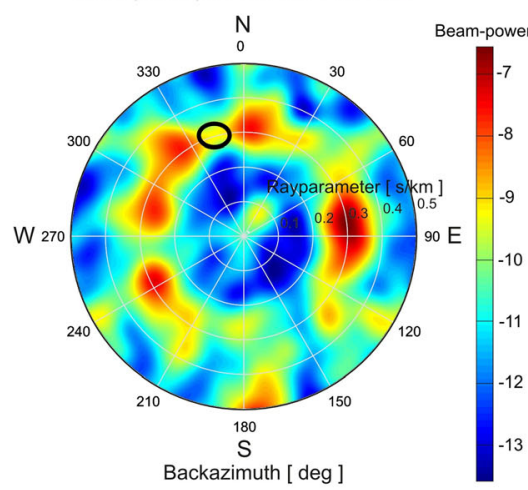

Beam-power plot 12062014-16-22(+4), Z

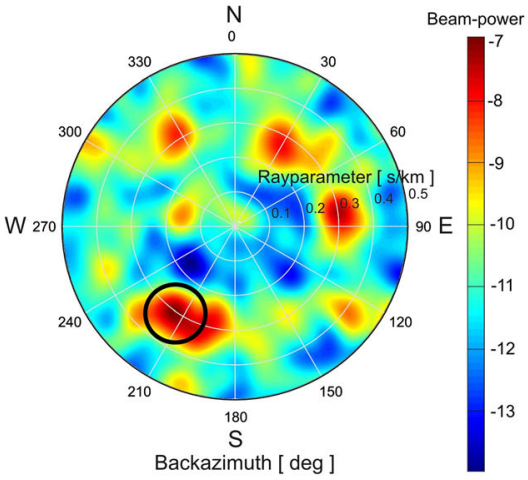

Beam-power plot 13062014-22-04(+4), Z

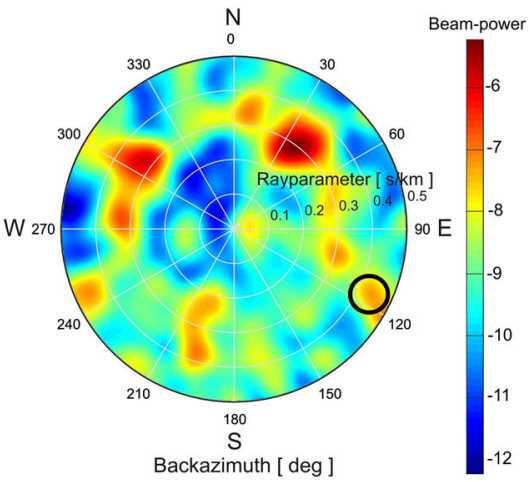

Beam-power plot 14062014-16-22(+4), Z

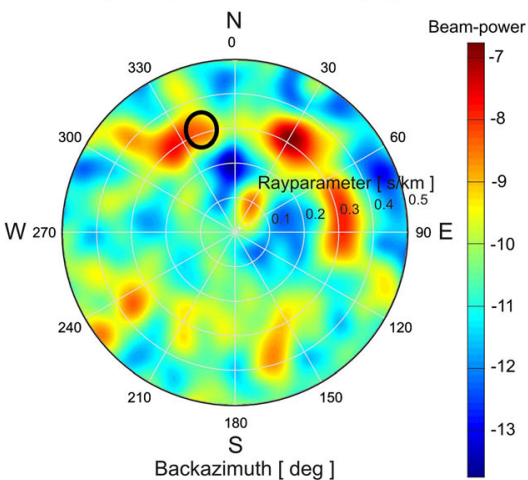

Fig. 8 Global distributions of significant wave height (left column: June 12, hour 18; June 14, hour 00; June 14, hour 18) compared with beam-power plots on $\mathrm{Z}$ component (middle and right columns) in real time (June 12, hours 12-18; June 13, hours 18-24; June 14, hours 12-18) and in 4-h time-delayed (June 12, hours 16-22; June 13, hours 22-04; June 14, hours 16-22). The beam-power is reported as a function of the azimuth $\left(0-359^{\circ}\right)$ and

in noise wavefield are interpretable as an increase of ocean wave heights due to strong storms and that the surface waves are generated when high, long-period waves hit the coastline. Here, we slowness (inverse of the velocity; $0.1-0.5 \mathrm{~s} / \mathrm{km}$ ). The beam-power colour scale is different for each plot to better highlight the dominant beams. Dates for the beam-power plots are reported as daymonthyear-starting hour-ending hour. Black ellipses/circles put in evidence SWH areas showing values $\geq 3.5 \mathrm{~m}$ and corresponding beam-power peaks considered in details in the text

study the ocean wave activity with the purpose of identifying the sources of primary microseisms and of Rayleigh and Love waves associated to long-period secondary microseisms much further 

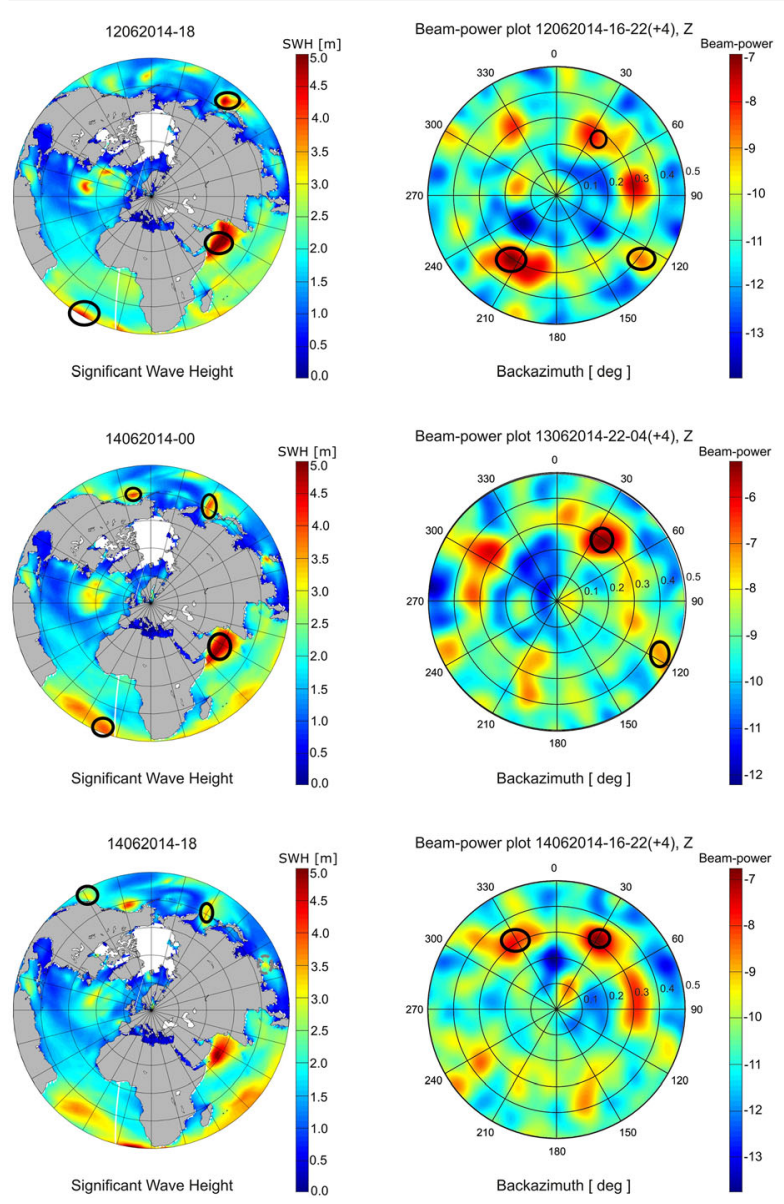

Fig. 9 Global distributions of significant wave height (first column on the left: June 12, hour 18; June 14, hour 00; June 14, hour 18) compared with beam-power plots on $\mathrm{Z}, \mathrm{N}$, and $\mathrm{E}$ components (second, third, and fourth columns) in 4-h time-delayed (June 12, hours 16-22; June 13, hours 22-04; June 14, hours 16-22). The beam-power is reported as a function of the azimuth $\left(0-359^{\circ}\right)$ and

from the array. To that, SWH data have been confronted with ambient noise beam-power for the $\mathrm{Z}, \mathrm{N}$, and $\mathrm{E}$ components. For strong storms in the Northern Indian Ocean, the Southern Atlantic Ocean, and the Northern Pacific Ocean, the global distributions of SWH are compared with the corresponding beam-power plots, on chosen hours in June 12-14, 2014 (Figs. 8 and 9), whereas for strong storms in the Northern Atlantic Ocean, the same comparison is performed in September 14-16(Fig. 10). Specifically, SWH maxima were analysed together with corresponding beampower peaks. As regards LPDF microseisms, Beucler et al. (2015) identify a few hour delay between the SWH maxima and the increases of
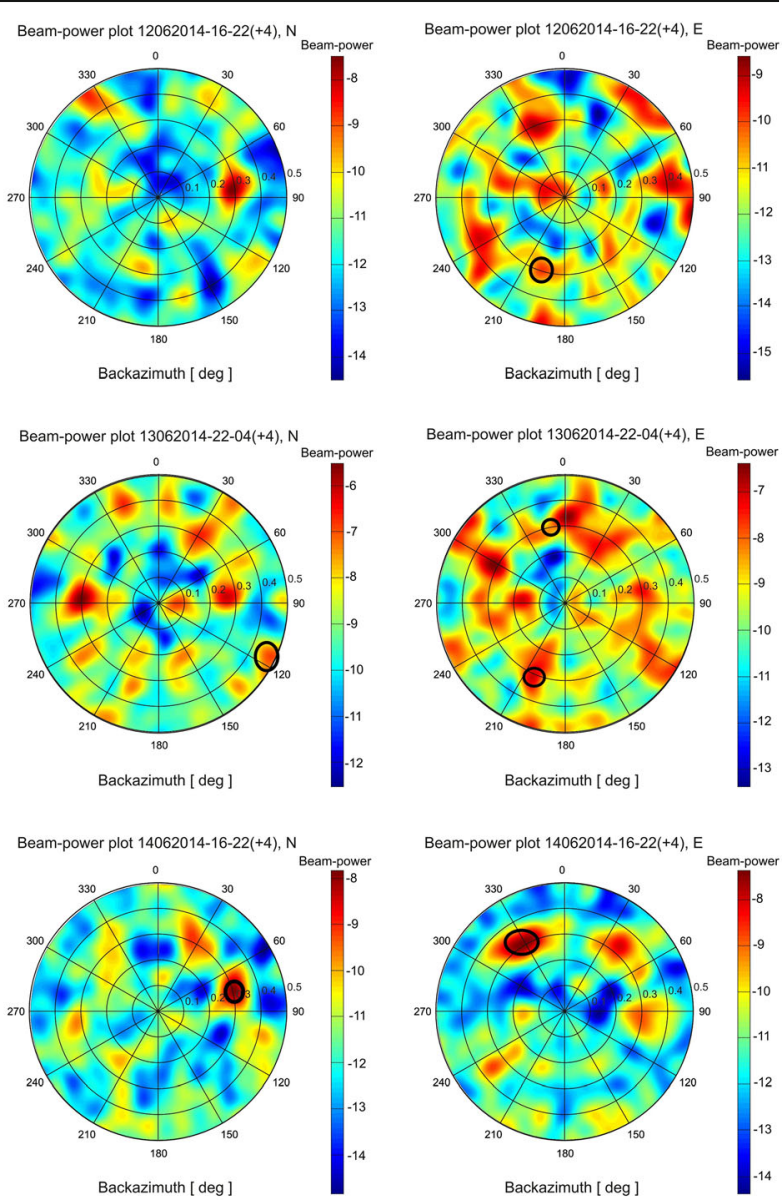

slowness (inverse of the velocity; $0.1-0.5 \mathrm{~s} / \mathrm{km}$ ). The beam-power colour scale is different for each plot to better highlight the dominant beams. Dates for the beam-power plots are reported as daymonthyear-starting hour-ending hour. Black ellipses/circles put in evidence SWH areas showing values $\geq 3.5 \mathrm{~m}$ and corresponding beam-power peaks considered in details in the text

noise energy, related to the time taken by swells to travel the distance from storm sources to the nearest shores. In the present work, by the combined analysis of the SWH charts every $6 \mathrm{~h}$ and the beam-power plots for each hour, we found that having considered a 4-h delay between SWH and beam-power allowed the improvement of the sharpness of the peaks. In Fig. 8, the SWH charts are compared with the beam-power plots for the $\mathrm{Z}$ component in real time and in the 4-h time delayed. On June 12, the beam-power peak around $210^{\circ}$, attributable to a strong storm in the Southern Atlantic Ocean, is noticeable but blurry in real time and sharper in time-delayed. On June 13, the peak around $110^{\circ}$, attributable to a strong 

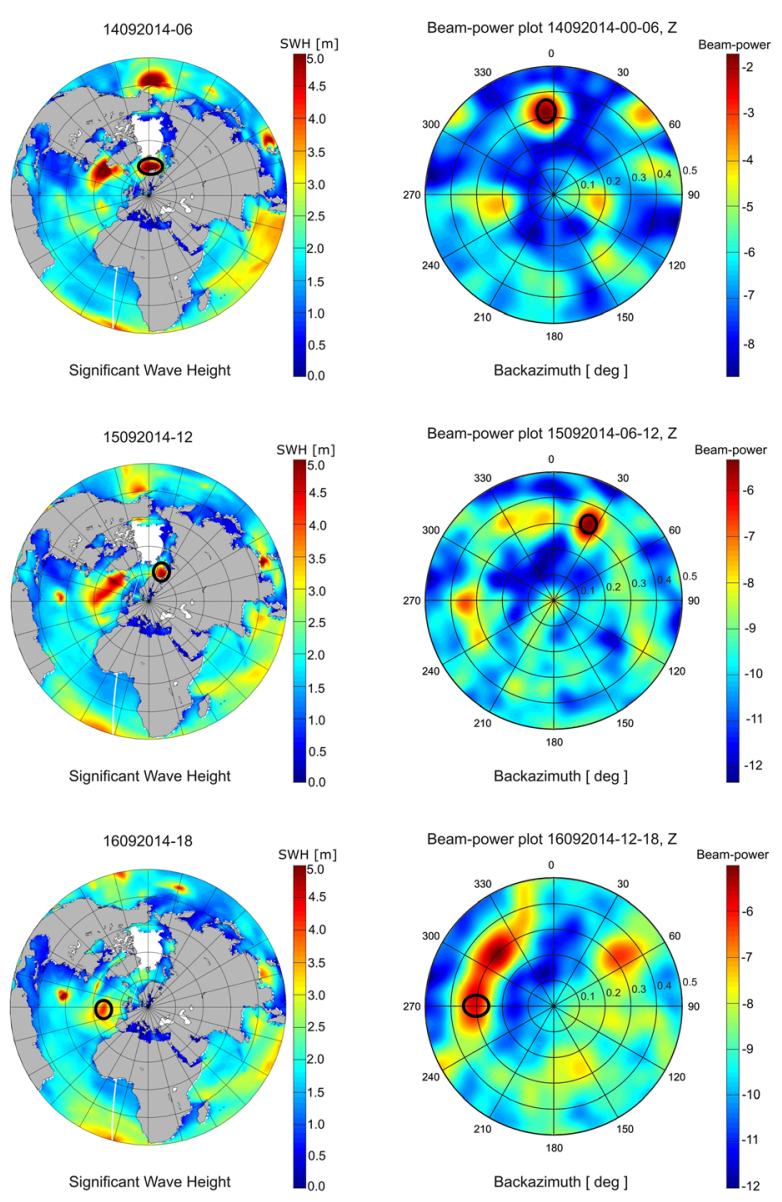

Fig. 10 Global distributions of significant wave height (first column on the left: September 14, hour 06; September 15, hour 12; September 16, hour 18) compared with beam-power plots on $\mathrm{Z}, \mathrm{N}$, and $\mathrm{E}$ components (second, third, and fourth columns) in real time (September 14, hours 00-06; September 15, hours 06-12; September 16, hours 12-18). The beam-power is reported as a function of the azimuth $\left(0-359^{\circ}\right)$ and slowness (inverse of the

storm in the Northern Indian Ocean, is weakly detectable in real time but cleaner in time-delayed. On June 14 , the peak around $350^{\circ}$, attributable to a strong storm in the Northern Pacific Ocean, is detectable only in time-delayed. Therefore, the sharpness of the beam-power peaks in real time, when high, long-period ocean waves are in the open sea, is rather lessened by undesired effects. On the other hand, the detectability of the same peaks in time-delayed, when such waves are hitting the coastline and surface waves are generated, is enhanced in that undesired effects are less noticeable. Since time-delayed results are sharper, only the beam-power was analysed for the $\mathrm{Z}, \mathrm{N}$,
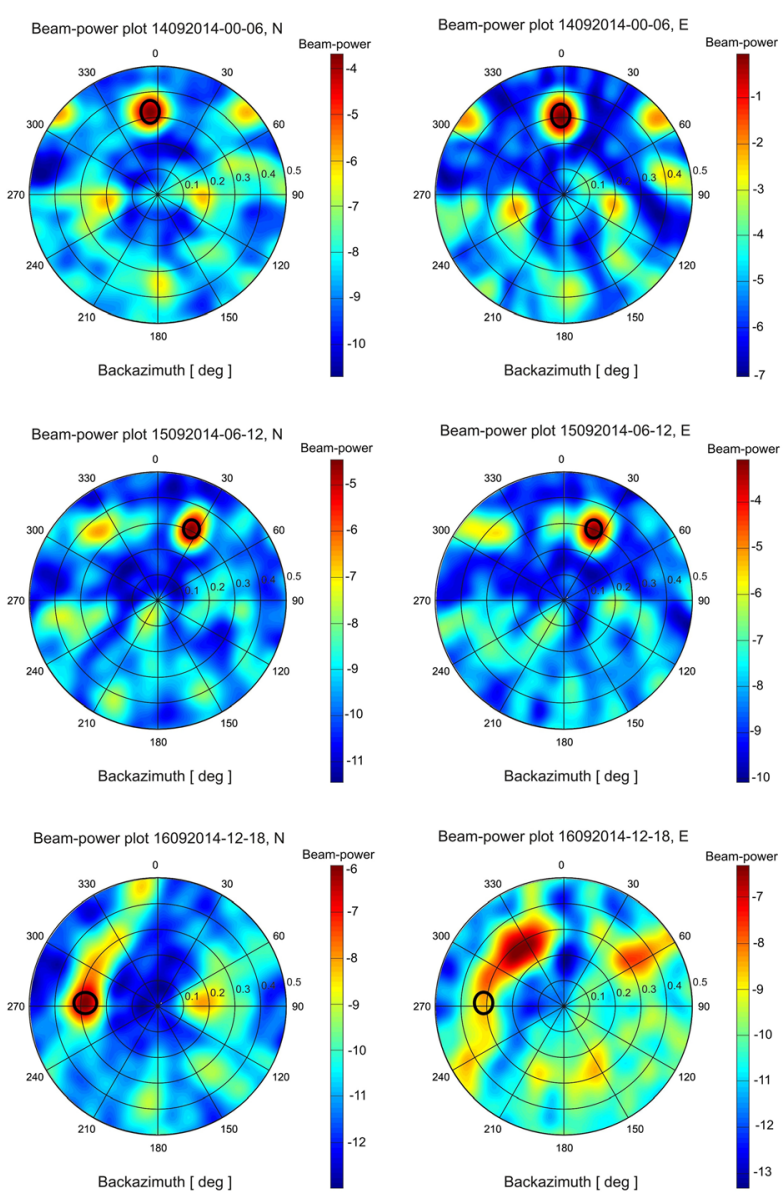

velocity; $0.1-0.5 \mathrm{~s} / \mathrm{km}$ ). The beam-power colour scale is different for each plot to better highlight the dominant beams. Dates for the beam-power plots are reported as daymonthyear-starting hourending hour. Black ellipses/circles put in evidence SWH areas showing values $\geq 3.5 \mathrm{~m}$ and corresponding beam-power peaks considered in details in the text

and E components to distinguish Rayleigh and Love waves. In Fig. 9, the global distributions of SWH are compared with the beam-power plots in 4-h time-delayed for the three components. On June 12, the specific beam-power peaks are analysed: on the $\mathrm{Z}$ component, around $30^{\circ}$ and $120^{\circ}$ attributable to strong storms in the Northern Pacific Ocean and the Northern Indian Ocean, respectively; on the $\mathrm{Z}$ and $\mathrm{E}$ components, around $210^{\circ}$ related to a strong storm in the Southern Atlantic Ocean; around $80^{\circ}$, on all the three components, probably caused by beamformer aliasing. On June 13, specific peaks are detected: on the $\mathrm{Z}$ component, around $40^{\circ}$ related to a strong storm in 
the Northern Pacific Ocean; on the $\mathrm{N}$ and $\mathrm{Z}$ components, around $120^{\circ}$ linked to a strong storm in the Northern Indian Ocean; on the E component, around 200 and $350^{\circ}$ attributable to strong storms in the Southern Atlantic Ocean and in the Northern Atlantic Ocean, respectively. On June 14, specific peaks are observed: on the $\mathrm{Z}$ component, around $30^{\circ}$ linked to a strong storm in Northern Pacific Ocean; on the $\mathrm{N}$ component, around $70^{\circ}$ attributable to a strong storm in the Northern $\mathrm{Pa}$ cific Ocean; on the $\mathrm{Z}$ and $\mathrm{E}$ components, around $330^{\circ}$ related to a strong storm in the Northern Pacific Ocean. The preceding analysis shows that surface waves, generated by ocean waves hitting the coastline around $230^{\circ}$ and $350^{\circ}$ and related to strong storms in the Southern Atlantic Ocean and the Northern Pacific Ocean, respectively, are detectable on the $\mathrm{Z}$ and $\mathrm{E}$ components of the beampower plots. On the other hand, surface waves generated by ocean waves hitting the coastline between 100 and $140^{\circ}$, attributable to a strong storm in the Northern Indian Ocean, are detectable on the $\mathrm{Z}$ and $\mathrm{N}$ components of the beam-power plots. Rayleigh waves associated to LPDF are predominantly observed along the N-S direction, while Love waves are mainly detected along the $\mathrm{E}-\mathrm{W}$ direction, in agreement with what was reported in the literature (Davy et al. 2015; Gal et al. 2017). With respect to source characterisation of primary microseisms, in Fig. 10, the SWH charts are compared with the beam-power plots for $\mathrm{Z}, \mathrm{N}$, and $E$ components in real-time (the comparison of SWH with beam-power on the $\mathrm{Z}$ component every $6 \mathrm{~h}$ on September $11-20,2014$ is reported as supplementary presentation). The beam-power peaks around $0^{\circ}$ (September 14), $20^{\circ}$ (September 15 ), and $270^{\circ}$ (September 16 ), corresponding to strong storms in the Northern Atlantic Ocean, are well-defined in that undesired effects are less noticeable. Thus, high, long-period ocean waves are expected to be generated very close to the coastline. The SWH maximum between 345 and $360^{\circ}$ on September 15, attributable to the strong storm that occurred in southern Greenland (source of SPDF microseisms) is not detectable in the beampower plots, being constituted of short-period ocean waves not reaching the coastline. The beam-power peak around $315^{\circ}$ on September 16, hours $12-18$, is not caused by aliasing and/or near- field effects but more likely by the large number, about 100 , of earthquakes recorded during that day in the area of Bárðarbunga (Iceland) with magnitude in the of 3.4-5.2 range (Icelandic Meteorological Office, 2015). Hence, in this case, the nature of the noise wavefield is not random. In summary, a significant correlation exists between SWH maxima and the detectable beam-power peaks during strong ocean storms. We have found a remarkable variability of noise wavefield azimuth and microseisms source location as a function of frequency. Sergeant et al. (2013) reports that this variability is largely related to the local bathymetry. For the storms in the Northern Indian Ocean (sources of LPDF microseisms dominated by Rayleigh waves), the Southern Atlantic, Ocean and the Northern Pacific Ocean (sources of LPDF microseisms dominated by Love waves), the 4-h delay between the SWH maxima and the related beampower peaks corresponds to the time needed by the long-period ocean waves to travel from the storm source to the coastline. No such delay has to be considered, instead, for the storms in the Northern Atlantic Ocean (sources of primary microseisms), in that such waves form very close to the coastline.

\section{Conclusions}

The temporal and spatial variations of the wavefield of the ambient noise, recorded at ' 13 BB star' array located in northern Poland from July 2013 to September 2016, was related to hitting on the coast of high, long-period ocean waves generated by strong storms in the Atlantic Ocean, the Northern Indian Ocean, and the Northern Pacific Ocean. Spectral analysis was applied to recognise the primary and secondary microseisms in the $0.04-0.1$ - and $0.2-0.8-\mathrm{Hz}$ frequency ranges, respectively. As for the primary microseism, the number and the amplitude of maxima, related to 1$\mathrm{h}$ power spectral density (PSD) curves, change on the basis of the intensity of the ocean storm. Concerning the secondary microseism, the splitting into two peaks, the first placed in the $0.2-0.3-\mathrm{Hz}$ range (long-period) and the second, in the 0.3-0.8$\mathrm{Hz}$ range (short-period), was observed. Highresolution three-component beamforming was 
applied on 1-h noise records to evaluate the temporal and spatial variations in the azimuth of noise sources and the velocity of surface waves. These changes were linked to the variations of the ocean wave height and period over a defined area during strong storms, through the combination of the observed data and forecast model results for the ocean waves, including wave-wave interactions and swells. The ocean wave activity was described by studying the global distribution of significant wave height $(\mathrm{SWH})$ together with the beam-power of the noise wavefield. That analysis allowed the detection of ocean storms and the identification of their duration, showing that the main source of noise wavefield is due to the high, long-period ocean waves hitting the coastlines. The source of long-period double-frequency (LPDF) microseisms was constituted of nonlinear interactions of such waves in the open sea able to reach the shore, linked to strong storms in the Northern Indian Ocean, the Southern Atlantic Ocean, and the Northern Pacific Ocean. A 1-h delay between the SWH maxima and the related beam-power peaks was identified as the time needed by the longperiod ocean waves to travel from the storm source to the coastline. The capabilities of the circular, symmetric structure of the ' 13 BB star' array allowed to distinguish the sources of Rayleigh waves (Northern Indian Ocean) and Love waves (Southern Atlantic Ocean and Northern Pacific Ocean), related to ocean waves hitting the coastline in the $100-140^{\circ}$ range and around 230 and $350^{\circ}$, respectively. On the other hand, the source of the primary microseism was attributable to the ocean wave activity during strong storms in the Northern Atlantic Ocean. No time delay was considered for these storms, because the longperiod ocean waves form very close to the coastline. Strong storms representing the source of short-period secondary microseisms were not detectable being constituted by short-period ocean waves not reaching the coastline.

Acknowledgements The observed data for ocean waves are provided by the National Center for Atmospheric Research (NCAR) reanalysis project (Kalnay et al. 1996) with a 1-h time resolution (International Comprehensive Ocean-Atmosphere Data Set (ICOADS), https://rda.ucar.edu/datasets/ds548.0/\#!imma1 subset.php?gindex $=1 \&$ da $=y$, Freeman et al. 2017). Forecast model results for ocean waves are supplied by European Centre for Medium-Range Weather Forecasts (ECMWF) with a 6-h time resolution (ERA-Interim project, https://www.ecmwf. $\mathrm{int} / \mathrm{en} /$ forecasts/datasets/reanalysis-datasets/era-interim, Dee et al. 2011). We thank Dr. Elmer Ruigrok, who developed the MATLAB codes used for calculations. The open-source GMT software (Wessel et al. 2013) was used for the maps.

Funding National Science Centre Poland provided financial support for this work through NCN grant DEC-2011/02/A/ST10/ 00284.

\section{Appendix 1. Resolution of the ' 13 BB star' array}

We want to establish the minimum number of stations of the ' 13 BB star' array (Fig. 11) necessary to identify the source of the noise wavefield on the basis of the spatial aliasing. As a test, BF was applied to the ambient noise recorded from 12:00 to 13:00 on February 20, 2014 along the $\mathrm{Z}$ component in the $0.05-0.1 \mathrm{~Hz}$ frequency band. The beam-power was initially calculated using only 5 stations: the azimuth of the first beam-power peak was identified at $302^{\circ}$ with a severe aliasing. The amplitude of this peak, indeed, was essentially the same as that of the peak caused by the aliasing. In this case, the distinction between the maxima was not evident, and thus, the evaluation was considered unsatisfying. Using 6 stations, the evaluation of the azimuth was $304^{\circ}$ for the first peak with a high aliasing. Indeed, the amplitude of this peak was equal to $-67.2 \mathrm{~dB}$, and the one of the second peak was equal to $-68.1 \mathrm{~dB}$. This estimation was considered still not acceptable because the amplitude difference between the two peaks was less than $1 \mathrm{~dB}$. Using 7 stations, the azimuth of the first beam-power peak was evaluated at $304^{\circ}$ with an amplitude equal to $-66.6 \mathrm{~dB}$, while the amplitude of the second peak was at $-68.1 \mathrm{~dB}$. This amplitude difference was considered satisfactory since it was larger than $1 \mathrm{~dB}$, meaning that the aliasing started to become lower than the threshold to get an acceptable array resolution. Using 10 stations, the evaluation of the azimuth was $301^{\circ}$ for the first beam-power peak with a low aliasing. The amplitude of this peak was equal to $-67.2 \mathrm{~dB}$, while the one of the second peak was equal to $-69.1 \mathrm{~dB}$ (almost $2 \mathrm{~dB}$ lower). Using all the 13 stations, the azimuth of the first peak was identified at $308^{\circ}$ with a weak aliasing. The amplitude difference, indeed, was more than $2 \mathrm{~dB}$. 

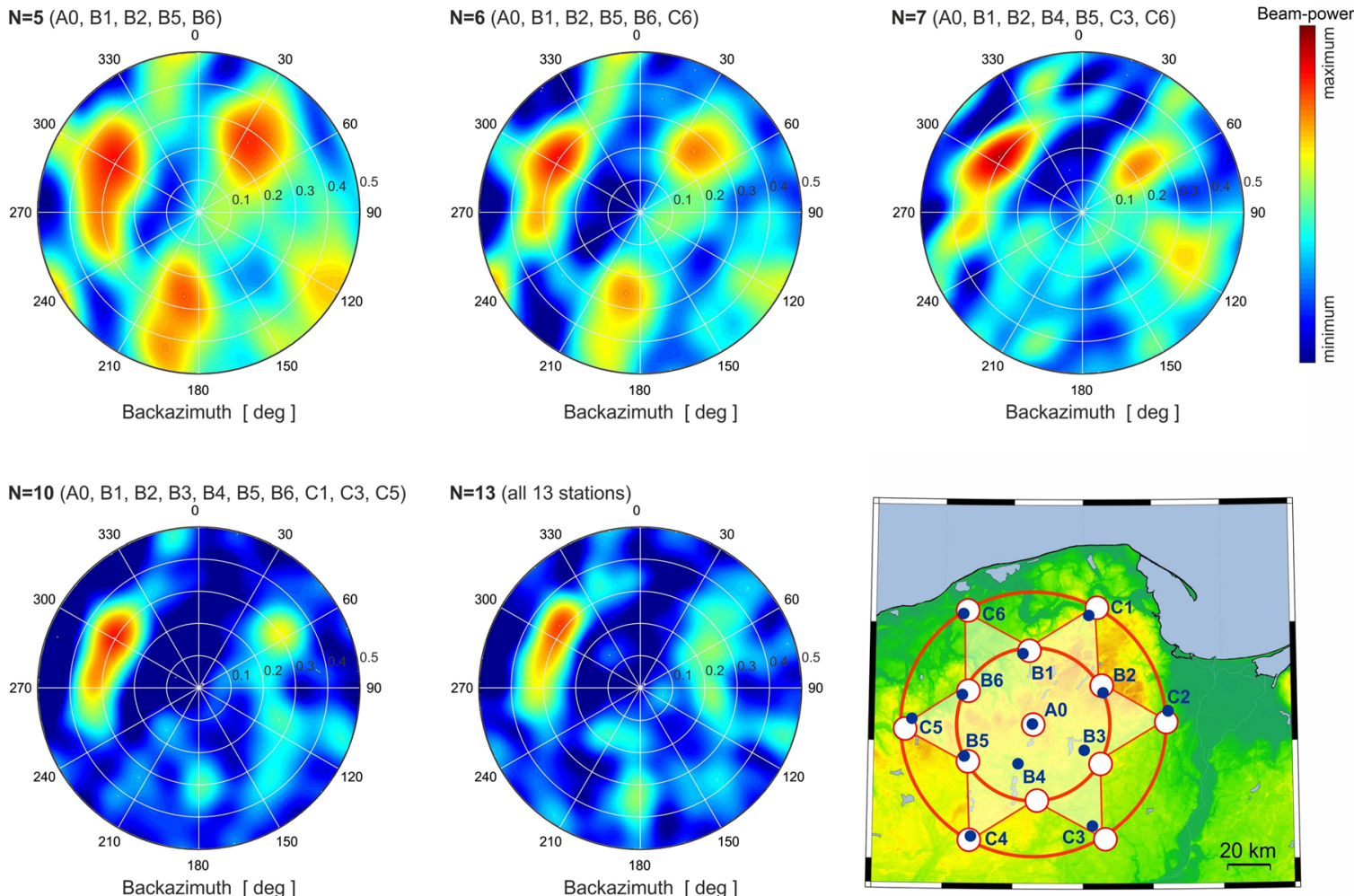

Fig. 11 Test of the ' 13 BB star' array resolution (bottom right plot) for increasing number of used stations. The beam-power began to be evaluated using five stations (top left plot), then six (top centre plot), seven (top right plot), ten (bottom left plot), and finally, all the 13 array stations (bottom centre plot). The beampower colour scale used for all the plots is reported in the top right extremity of the figure

\section{Appendix 2. Procedure to obtain significant wave height}

The significant wave height ( $\mathrm{SWH})$ is obtained by analysing the observed data and the forecast model results for wave height and period. The observed data are shown in Fig. 12, where wave (a) height and (b) period for January 9, 2014, hour 0, are plotted in geographic coordinates on a Mercator projection with scaling factor equal to 1 . The observed wave height varies from $1 \mathrm{~m}$ to at least $12 \mathrm{~m}$. The waves having a height within the 2-6 $\mathrm{m}$ range are the ones showing generally a long period. The observed wave period ranges from 2 to at least $16 \mathrm{~s}$. Long-period waves (> $11 \mathrm{~s})$ are not generated by local winds, but they have remote origins, such as the Atlantic Ocean storms. As it can be seen, the geographical coverage of the observed data for the wave height and the period is very limited. Thus, a first guess of SWH was performed by Gauss-Markov smoothing, assuming the covariance is homogeneous and isotropic. Afterwards, the new set was joined with the forecast model results, including wave-wave interactions and swells, to get the SWH in spherical coordinates as a function of the azimuth and the distance between the storm sources and the A0 station. 


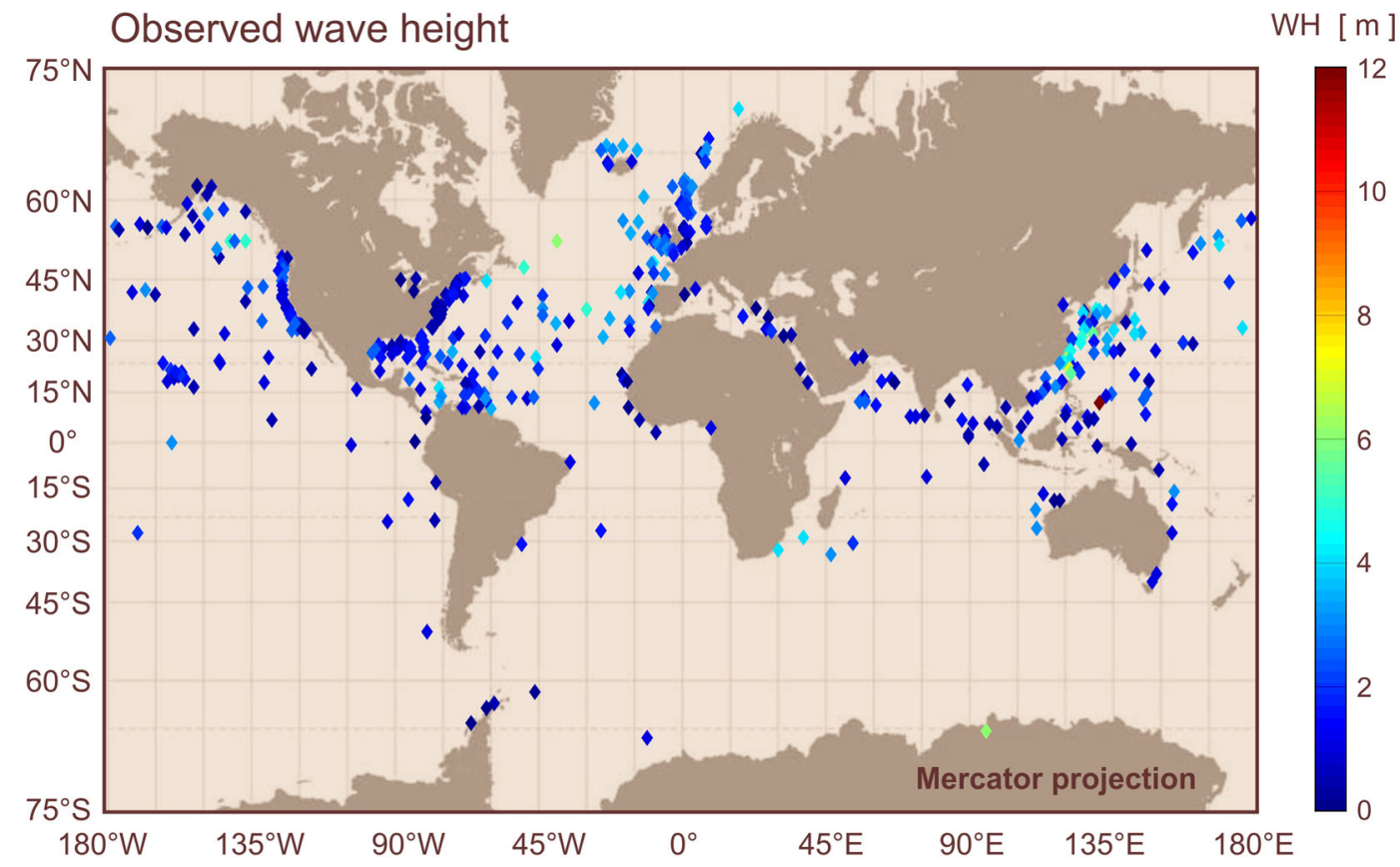

Observed wave period

WP [ s ]

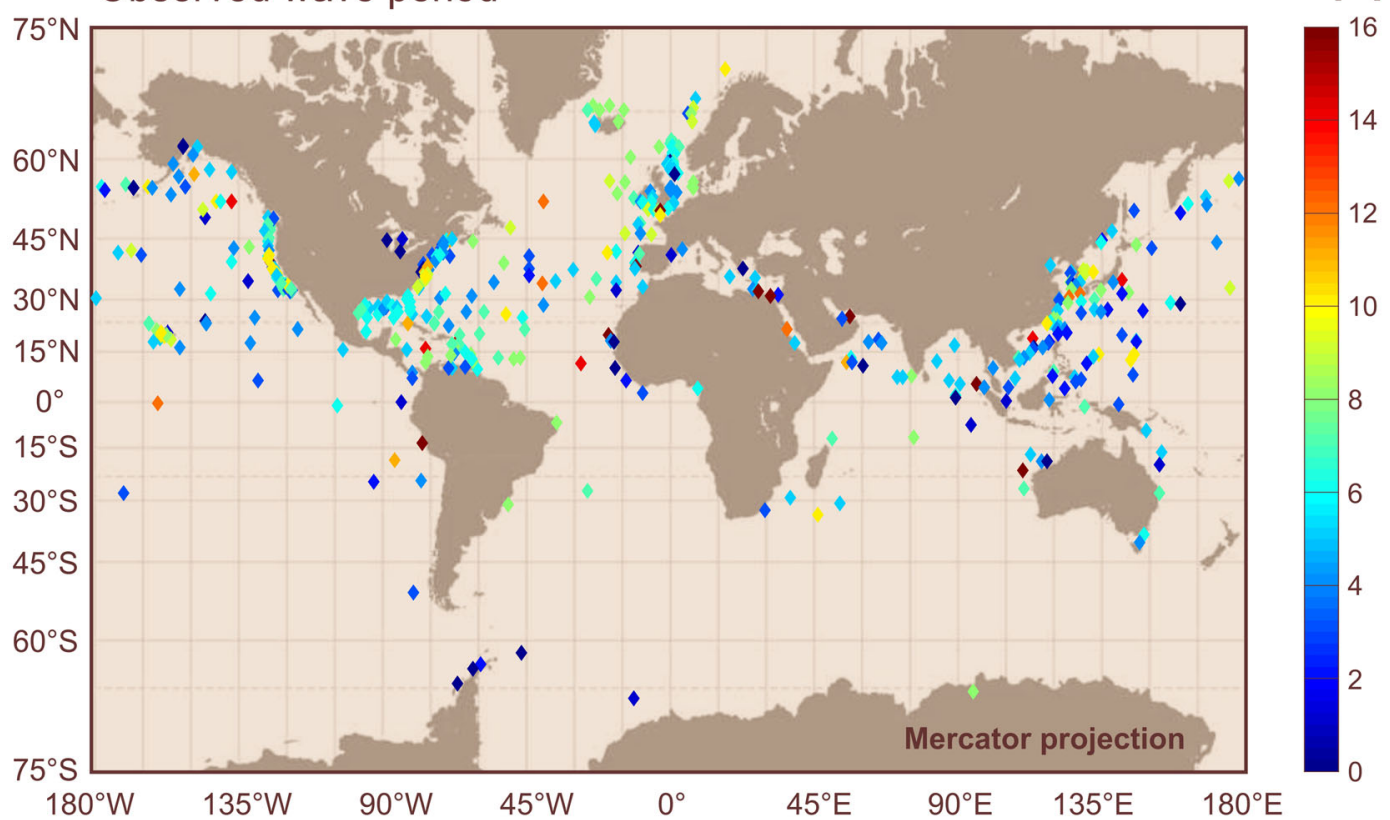

Fig. 12 Observed data for wave height (WH, in meters: top) and wave period (WP, in seconds: bottom) plotted on a Mercator projection with scaling factor equal to 1 . The best geographical coverage is displayed in the Atlantic Ocean (from $90^{\circ} \mathrm{W}$ up to $15^{\circ} \mathrm{E}$ ), in the Northern Indian Ocean (from $50^{\circ} \mathrm{E}$ up to $100^{\circ} \mathrm{E}$ ), and in the Northern Pacific Ocean (from $135^{\circ} \mathrm{E}$ up to $45^{\circ} \mathrm{W}$ ). Wave height varies from 1 to at least $12 \mathrm{~m}$, while wave period ranges from 1 to at least $16 \mathrm{~s}$ 
Open Access This article is licensed under a Creative Commons Attribution 4.0 International License, which permits use, sharing, adaptation, distribution and reproduction in any medium or format, as long as you give appropriate credit to the original author(s) and the source, provide a link to the Creative Commons licence, and indicate if changes were made. The images or other third party material in this article are included in the article's Creative Commons licence, unless indicated otherwise in a credit line to the material. If material is not included in the article's Creative Commons licence and your intended use is not permitted by statutory regulation or exceeds the permitted use, you will need to obtain permission directly from the copyright holder. To view a copy of this licence, visit http://creativecommons.org/licenses/by/4.0/.

\section{References}

Ardhuin F, Stutzmann E, Schimmel M, Mangeney A (2011) Ocean wave sources of seismic noise. J Geophys Res 116: C09004. https://doi.org/10.1029/2011JC006952

Ardhuin F, Balanche A, Stutzmann E, Obrebski M (2012) From seismic noise to ocean wave parameters: General methods and validation. J Geophys Res 117(C5):C05002. https://doi. org/10.1029/2011JC007449

Ardhuin F, Gualtieri L, Stutzmann E (2015) How ocean waves rock the earth: Two mechanisms explain microseisms with periods 3 to $300 \mathrm{~s}$. Geophys Res Lett 42:765-772. https://doi. org/10.1002/2014GL062782.1

Behr Y, Townend J, Bowen M, Carter L, Gorman R, Brooks L, Bannister S (2013) Source directionality of ambient seismic noise inferred from three-component beamforming. $\mathrm{J}$ Geophys Res 118:240-248. https://doi.org/10.1029/2012 JB009382

Bensen G, Ritzwoller M, Barmin M, Levshin A, Lin F, Moschetti M, Shapiro NM, Yang Y (2007) Processing seismic ambient noise data to obtain reliable broad-band surface wave dispersion measurements. Geophys J Int 169:1239-1260. https://doi.org/10.1111/j.1365-246X.2007.03374.x

Beucler É, Mocquet A, Schimmel M, Chevrot S, Quillard O, Vergne J, Sylvander M (2015) Observation of deep water microseisms in the North Atlantic Ocean using tide modulations. Geophys Res Lett 42:316-322. https://doi.org/10.1002 /2014GL062347

Bromirski PD, Duennebier FK (2002) The near-coastal microseism spectrum: Spatial and temporal wave climate relationships. J Geophys Res 107(B8):2166. https://doi.org/10.1029 /2001JB000265

Bromirski PD, Duennebier FK, Stephen RA (2005) Mid-ocean microseisms. Geochem Geophys Geosyst 6:Q04009. https://doi.org/10.1029/2004GC000768

Bromirski PD, Stephen RA, Gerstoft P (2013) Are deep-oceangenerated surface-wave microseisms observed on land? J Geophys Res 118:3610-3629. https://doi.org/10.1002 /jgrb.50268

Cessaro RK, Chan WW (1989) Wide-angle triangulation array study of simultaneous primary microseism sources. J Geophys Res 94:15555-15563. https://doi.org/10.1029 /JB094iB11p15555
Chevrot S, Sylvander M, Benahmed S, Ponsolles C, Lefèvre JM, Paradis D (2007) Source locations of secondary microseisms in western Europe: Evidence for both coastal and pelagic sources. J Geophys Res 112:B11301. https://doi. org/10.1029/2007JB005059

Davy C, Stutzmann E, Barruol G, Fontaine F, Schimmel M (2015) Sources of secondary microseisms in the Indian Ocean. Geophys J Int 202:1180-1189. https://doi.org/10.1093 /gji/ggv221

Dee DP, Uppala SM, Simmons AJ, Berrisford P, Poli P, Kobayashi S, Andrae U, Balmaseda MA, Balsamo G, Bauer P, Bechtold P, Beljaars ACM, van de Berg L, Bidlot J, Bormann N, Delsol C, Dragani R, Fuentes M, Geer AJ, Haimberger L, Healy SB, Hersbach H, Hólm EV, Isaksen L, Kållberg P, Köhler M, Matricardi M, McNally AP, MongeSanz BM, Morcrette J-J, Park B-K, Peubey C, de Rosnay P, Tavolato C, Thépaut J-N, Vitart F (2011) The ERA-interim reanalysis: Configuration and performance of the data assimilation system. Q J R Meteorol Soc 137:553-597. https://doi. org/10.1002/qj.828

Demuth A, Ottemöller L, Keers H (2016) Ambient noise levels and detection threshold in Norway. J Seism 20:889-904. https://doi.org/10.1007/s10950-016-9566-8

Ebeling CW (2012) Inferring ocean storm characteristics from ambient seismic noise: A historical perspective. Adv Geophys 53:1-33. https://doi.org/10.1016/B978-0-12380938-4.00001-X

Essen H-H, Krger F, Dahm T, Grevemeyer I (2003) On the generation of secondary microseisms observed in northern and Central Europe. J Geophys Res 108(B10):2506. https://doi.org/10.1029/2002JB002338

Freeman E, Woodruff SD, Worley SJ, Lubker SJ, Kent EC, Angel WE, Berry DI, Brohan P, v Eastman R, Gates L, Gloeden W, Ji Z, Lawrimore J, Rayner NA, Rosenhageni G, Smith SR (2017) ICOADS Release 3.0: A major update to the historical marine climate record. Int J Climatol 37:2211-2232. https://doi.org/10.1002/joc.4775

Friedrich A, Kruger F, Klinge K (1998) Ocean-generated microseismic noise located with the Grafenberg array. J Seismol 2: 47-64. https://doi.org/10.1023/A:1009788904007

Gal M, Reading AM, Ellingsen S, Koper KD, Burlacu R, Gibbons SJ (2016) Deconvolution enhanced direction of arrival estimation using one- and three-component seismic arrays applied to ocean induced microseisms. Geophys J Int 206:345359. https://doi.org/10.1093/gji/ggw150

Gal M, Reading AM, Ellingsen SP, Koper KD, Burlacu R (2017) Full wavefield decomposition of high-frequency secondary microseisms reveals distinct arrival azimuths for Rayleigh and Love waves. J. Geophys. Res. Solid Earth 122:4660 4675. https://doi.org/10.1002/2017JB014141

Gerstoft P, Tanimoto T (2007) A year of microseisms in southern California. Geophys Res Lett 34:L20304. https://doi. org/10.1029/2007GL031091

Grad M, Polkowski M, Wilde-Píorko M, Suchcicki J, Arant T (2015) Passive seismic experiment '13 BB star' in the margin of the east European Craton, Northern Poland. Acta Geophys 63:352-373. https://doi.org/10.1515/acgeo-2015-0006

Gualtieri L, Stutzmann E, Capdeville Y, Farra V, Mangeney A, Morelli A (2015) On the shaping factors of the secondary microseismic wavefield. J. Geophys. Res. Solid Earth 120: 6241-6262. https://doi.org/10.1002/2015JB012157 
Harmon N, Gerstoft P, Rychert AC, Abers GA, de la Cruz MS, Fischer KM (2008) Phase velocities from seismic noise using beamforming and cross-correlation in Costa Rica and Nicaragua. Geophys Res Lett 35:L19303. https://doi. org/10.1029/2008GL035387

Harmon N, Rychert AC, Gerstoft P (2010) Distribution of noise sources for seismic interferometry. Geophys J Int 183:1470 1484. https://doi.org/10.1111/j.1365-246X.2010.04802.x

Hasselmann K (1963) A statistical analysis of the generation of microseisms. Rev Geophys 1:177-209. https://doi. org/10.1029/RG001i002p00177

Haubrich RA, McCamy K (1969) Microseisms: coastal and pelagic sources. Rev Geophys 7:539-571. https://doi. org/10.1029/RG007i003p00539

Hillers G, Graham N, Campillo M, Kedar S, Landès M, Shapiro NM (2012) Global oceanic microseism sources as seen by seismic arrays and predicted by wave action models. Geochem Geophys Geosyst 13:1-19. https://doi. org/10.1029/2011GC003875

Icelandic Meteorological Office (2015). Bárðarbunga 2014 September events. https://en.vedur.is/earthquakes-andvolcanism/articles/nr/3001\#sep16

Juretzek C, Hadziioannou C (2016) Where do ocean microseisms come from? A study of Love-to-Rayleigh wave ratios. J. Geophys. Res. Solid Earth 121:6741-6756. https://doi. org/10.1002/2016JB013017

Juretzek C, Hadziioannou C (2017) Linking source region and ocean wave parameters with the observed primary microseismic noise. Geophys J Int 211:1640-1654. https://doi. org/10.1093/gii/ggx388

Kalnay E, Kanamitsu M, Kistler R, Collins W, Deaven D, Gandin L, Iredell M, Saha S, White G, Woollen J, Zhu Y, Chelliah M, Ebisuzaki W, Higgins W, Janowiak J, Mo KC, Ropelewski C, Wang J, Leetmaa A, Reynolds R, Jenne R, Joseph D (1996) The NCEP/NCAR 40-year reanalysis project. Bull Am Meteorol Soc 77:437-471. https://doi. org/10.1175/1520-0477(1996)077<0437:TNYRP>2.0.CO;2

Kedar S, Longuet-Higgins M, Webb F, Graham N, Clayton R, Jones C (2008) The origin of deep ocean microseisms in the North Atlantic Ocean. Proc R Soc Lond A 464:777-793. https://doi.org/10.1098/rspa.2007.0277

Koper KD, Burlacu R (2015) The fine structure of doublefrequency microseisms recorded by seismometers in North America. J. Geophys. Res. Solid Earth 120:1677-1691. https://doi.org/10.1002/2014JB011820

Koper KD, de Foy B, Benz H (2009) Composition and variation of noise recorded at the Yellowknife Seismic Array, 19912007. J Geophys Res 114:B10310. https://doi.org/10.1029 /2009JB006307

Kurrle D, Widmer-Schnidrig R (2010) Excitation of long-period Rayleigh waves by large storms over the North Atlantic Ocean. Geophys J Int 183:330-338. https://doi.org/10.1111 /j.1365-246X.2010.04723.x

Lacoss RT, Kelly EJ, Toksöz MN (1969) Estimation of seismic noise structure using arrays. Geophysics 34:21-38. https://doi.org/10.1190/1.1439995

Landès M, Hubans F, Shapiro NM, Paul A, Campillo M (2010) Origin of deep ocean microseisms by using teleseismic body waves. J Geophys Res 115:1-14. https://doi.org/10.1029 /2009JB006918
Lee A (1935) On the direction of approach of microseismic waves. Proc. R. Soc. Lond., A: Math. Phys Sci 149:183-199. https://doi.org/10.1098/rspa.1935.0056

Lepore S, Grad M (2018) Analysis of the primary and secondary microseisms in the wavefield of the ambient noise recorded in northern Poland. Acta Geophys 66:915-929. https://doi. org/10.1007/s11600-018-0194-2

Lepore S, Markowicz KM, Grad M (2016) Impact of wind on ambient noise recorded by seismic array in northern Poland. Geophys J Int 205:1406-1413. https://doi.org/10.1093 /gji/ggw093

Longuet-Higgins MS (1950) A theory on the origin of microseisms. Philos Trans R Soc London 243:1-35. https://doi. org/10.1098/rsta.1950.0012

Möllhoff M, Bean CJ (2016) Seismic noise characterization in proximity to strong microseism sources in the Northeast Atlantic. Bull Seismol Soc Am 106:464 477. https://doi. org/10.1785/0120150204

Nishida K, Kawakatsu H, Fukao Y, Obara K (2008) Background Love and Rayleigh waves simultaneously generated at the Pacific Ocean floors. Geophys Res Lett 35:L16307. https://doi.org/10.1029/2008g1034753

Obrebski MJ, Ardhuin F, Stutzmann E, Schimmel M (2012) How moderate sea states can generate loud seismic noise in the deep ocean. Geophys Res Lett 39:L11601. https://doi. org/10.1029/2012GL051896

Palmer TN, Brankovic C, Molteni F, Tibaldi S, Ferranti L, Hollingsworth A, Cubasch U, Klinker E (1990) The European Centre for Medium-Range Weather Forecasts (ECMWF) program on extended-range prediction. Bull Amer Meteor Soc 71:1317-1330. https://doi.org/10.1175 /1520-0477(1990)071<1317:TECFMR >2.0.CO;2

Peterson (1993) Observation and modeling of seismic background noise. U.S. Geol Surv Tech Rept 93-322:1-95. https://doi. org/10.3133/ofr93322

Rost S, Thomas C (2002) Array seismology: methods and applications. Rev Geophys 40(2):1-27. https://doi.org/10.1029 /2000RG000100

Roux P (2009) Passive seismic imaging with directive ambient noise: application to surface waves and the San Andreas Fault in Parkfield. CA Geophys J Int 179:367-373. https://doi. org/10.1111/j.1365-246X.2009.04282.x

Ruigrok E, Campman X, Wapenaar CPA (2011) Extraction of Pwave reflections from microseisms. Compt Rendus Geosci 343:512-525. https://doi.org/10.1016/j.crte.2011.02.006

Sabra KG, Gerstoft P, Roux P, Kuperman WA (2005) Surface wave tomography from microseisms in Southern California. Geophys Res Lett 32:L14311. https://doi.org/10.1029/2005 GL023155

Schimmel M, Stutzmann E, Ardhuin F, Gallart J (2011) Polarized Earth's ambient microseismic noise. Geochem Geophys Geosyst 12:Q07014. https://doi.org/10.1029/2011 GC003661

Schimmel M, Stutzmann E, Ventosa S (2017) Measuring group velocity in seismic noise correlation studies based on phase coherence and resampling strategies. IEEE Trans Geosci Remote Sens 55:1928-1935. https://doi.org/10.1109 /TGRS.2016.2631445

Schulte-Pelkum V, Earle PS, Vernon FL (2004) Strong directivity of ocean-generated seismic noise. Geochem Geophys Geosyst 5:Q03004. https://doi.org/10.1029/2003GC000520 
Sergeant A, Stutzmann E, Maggi A, Schimmel M, Ardhuin F, Obrebski M (2013) Frequency-dependent noise sources in the North Atlantic Ocean. Geochem Geophys Geosyst 14: 5341-5353. https://doi.org/10.1002/2013GC004905

Seydoux L, Shapiro NM, de Rosny J, Landès M (2016) Spatial coherence of the seismic wavefield continuously recorded by the USArray. Geophys Res Lett 43:9644-9652. https://doi. org/10.1002/2016GL070320

Shapiro NM, Campillo M (2004) Emergence of broadband Rayleigh waves from correlations of the ambient seismic noise. Geophys Res Lett 31:L07614. https://doi.org/10.1029 /2004GL019491

Stehly L, Campillo M, Shapiro NM (2006) A study of the seismic noise from its long-range correlation properties. J Geophys Res 111:B10306. https://doi.org/10.1029/2005JB004237

Stopa JE, Ardhuin F, Stutzmann E, Lecocq T (2019) Sea state trends and variability: consistency between models, altimeters, buoys, and seismic data (1979-2016). J Geophys Res Oceans 124:3923-3940. https://doi.org/10.1029/2018 JC014607

Stutzmann E, Ardhuin F, Schimmel M, Mangeney A, Patau G (2012) Modeling long-term seismic noise in various environments. Geophys J Int 191:707-722. https://doi.org/10.1111 /j.1365-246X.2012.05638.x

Tanimoto T, Prindle K (2007) Surface wave analysis with beamforming. Earth Planets Space 59:453-458. https://doi. org/10.1111/j.1365-246X.2006.02931.x

Tanimoto T, Ishimaru S, Alvizuri C (2006) Seasonality in particle motion of microseisms. Geophys J Int 166:253-266. https://doi.org/10.1111/j.1365-246X.2006.02905.x van Dalen KN, Wapenaar CPA, Halliday DF (2014) Surface wave retrieval in layered media using seismic interferometry by multidimensional deconvolution. Geophys J Int 196:230242. https://doi.org/10.1093/gji/ggt389

Webb SC, Zhang X, Crawford W (1991) Infragravity waves in the deep ocean. J Geophys Res 96:2723-2736. https://doi. org/10.1029/90JC02212

Wessel P, Smith WHF, Scharroo R, Luis JF, Wobbe F (2013) Generic mapping tools: Improved version released. EOS Trans AGU 94:409-410. https://doi.org/10.1002/2013 EO450001

Wilson D, Leon J, Aster R, Ni J, Schlue J, Grand S, Semken S, Baldridge S, Gao W (2002) Broadband seismic background noise at temporary seismic stations observed on a regional scale in the southwestern United States. Bull Seismol Soc Am 92:3335-3342. https://doi.org/10.1785/0120010234

Xiao H, Xue M, Yang T, Liu C, Hua Q, Xia S, Huang H, Le BM, Yu Y, Huo D, Pan M, Li L, Gao J (2018) The characteristics of microseisms in South China Sea: results from a combined data set of OBSs, broadband land seismic stations, and a global wave height model. J. Geophys. Res. Solid Earth 123:3923-3942. https://doi.org/10.1029/2017jb015291

Yang Y, Ritzwoller MH (2008) Characteristics of ambient seismic noise as a source for surface wave tomography. Geochem Geophys Geosyst 9:1-18. https://doi.org/10.1029/2007 GC001814

Publisher's note Springer Nature remains neutral with regard to jurisdictional claims in published maps and institutional affiliations. 